\title{
The Roland von Glasow Air-Sea-Ice Chamber (RvG-ASIC): an experimental facility for studying ocean-sea-ice-atmosphere interactions
}

\author{
Max Thomas ${ }^{1,2}$, James France ${ }^{1,3,4}$, Odile Crabeck ${ }^{1,5,6}$, Benjamin Hall ${ }^{7}$, Verena Hof ${ }^{8}$, Dirk Notz ${ }^{8,9}$, Tokoloho Rampai ${ }^{7}$, \\ Leif Riemenschneider ${ }^{8}$, Oliver John Tooth ${ }^{1}$, Mathilde Tranter ${ }^{1}$, and Jan Kaiser ${ }^{1}$ \\ ${ }^{1}$ Centre for Ocean and Atmospheric Sciences, School of Environmental Sciences, University of East Anglia, \\ NR4 7TJ, Norwich, UK \\ ${ }^{2}$ Department of Physics, University of Otago, P.O. Box 56, Dunedin 9054, New Zealand \\ ${ }^{3}$ British Antarctic Survey, Natural Environment Research Council, Cambridge CB3 OET, UK \\ ${ }^{4}$ Department of Earth Sciences, Royal Holloway, University of London, Egham TW20 0EX, UK \\ ${ }^{5}$ Laboratoire de Glaciologie, Université Libre de Bruxelles, Bruxelles, Belgium \\ ${ }^{6}$ Unité d'Océanographie Chimique, Freshwater and Oceanic sCience Unit reSearch (FOCUS), \\ Université de Liége, Liége, Belgium \\ ${ }^{7}$ Chemical Engineering Department, University of Cape Town, Cape Town, South Africa \\ ${ }^{8}$ Max Planck Institute for Meteorology, Hamburg, Germany \\ ${ }^{9}$ Center for Earth System Research and Sustainability (CEN), University of Hamburg, Hamburg, Germany
}

Correspondence: Jan Kaiser (j.kaiser@uea.ac.uk)

Received: 29 September 2020 - Discussion started: 14 October 2020

Revised: 6 January 2021 - Accepted: 27 January 2021 - Published: 5 March 2021

\begin{abstract}
Sea ice is difficult, expensive, and potentially dangerous to observe in nature. The remoteness of the Arctic Ocean and Southern Ocean complicates sampling logistics, while the heterogeneous nature of sea ice and rapidly changing environmental conditions present challenges for conducting process studies. Here, we describe the Roland von Glasow Air-Sea-Ice Chamber (RvG-ASIC), a laboratory facility designed to reproduce polar processes and overcome some of these challenges. The RvG-ASIC is an open-topped $3.5 \mathrm{~m}^{3}$ glass tank housed in a cold room (temperature range: -55 to $\left.+30^{\circ} \mathrm{C}\right)$. The RvG-ASIC is equipped with a wide suite of instruments for ocean, sea ice, and atmospheric measurements, as well as visible and UV lighting. The infrastructure, available instruments, and typical experimental protocols are described.

To characterise some of the technical capabilities of our facility, we have quantified the timescale over which our chamber exchanges gas with the outside, $\tau_{1}=(0.66 \pm 0.07) \mathrm{d}$, and the mixing rate of our experimental ocean, $\tau_{\mathrm{m}}=(4.2 \pm$ $0.1)$ min. Characterising our light field, we show that the light intensity across the tank varies by less than $10 \%$ near the
\end{abstract}

centre of the tank but drops to as low as $60 \%$ of the maximum intensity in one corner. The temperature sensitivity of our light sources over the 400 to $700 \mathrm{~nm}$ range (PAR) is $(0.028 \pm 0.003) \mathrm{W} \mathrm{m}^{-2}{ }^{\circ} \mathrm{C}^{-1}$, with a maximum irradiance of $26.4 \mathrm{~W} \mathrm{~m}^{-2}$ at $0^{\circ} \mathrm{C}$; over the 320 to $380 \mathrm{~nm}$ range, it is $(0.16 \pm 0.1) \mathrm{W} \mathrm{m}^{-2}{ }^{\circ} \mathrm{C}^{-1}$, with a maximum irradiance of $5.6 \mathrm{~W} \mathrm{~m}^{-2}$ at $0^{\circ} \mathrm{C}$.

We also present results characterising our experimental sea ice. The extinction coefficient for PAR varies from 3.7 to $6.1 \mathrm{~m}^{-1}$ when calculated from irradiance measurements exterior to the sea ice and from 4.4 to $6.2 \mathrm{~m}^{-1}$ when calculated from irradiance measurements within the sea ice. The bulk salinity of our experimental sea ice is measured using three techniques, modelled using a halo-dynamic one-dimensional (1D) gravity drainage model, and calculated from a salt and mass budget. The growth rate of our sea ice is between 2 and $4 \mathrm{~cm} \mathrm{~d}^{-1}$ for air temperatures of $(-9.2 \pm 0.9)^{\circ} \mathrm{C}$ and $(-26.6 \pm 0.9)^{\circ} \mathrm{C}$. The PAR extinction coefficients, vertically integrated bulk salinities, and growth rates all lie within the range of previously reported comparable values for first-year sea ice. The vertically integrated bulk salinity and growth 
rates can be reproduced well by a $1 \mathrm{D}$ model. Taken together, the similarities between our laboratory sea ice and observations in nature, as well as our ability to reproduce our results with a model, give us confidence that sea ice grown in the RvG-ASIC is a good representation of natural sea ice.

\section{Introduction}

Sea ice lies at the ocean-atmosphere interface. As such, sea ice mediates the exchange of energy (e.g. Grenfell and Maykut, 1977), momentum (e.g. McPhee et al., 1987), gases (e.g. Gosink et al., 1976), and particles (e.g. May et al., 2016) between the polar oceans and the atmosphere. Sea-ice formation provides buoyancy forcing to the underlying ocean (Worster and Rees Jones, 2015). Sea-ice algae inhabit brine inclusions in the sea ice and can reach high concentrations, with nutrients resupplied by gravity drainage (Fritsen et al., 1994).

The remoteness and extremeness typical of the polar oceans make observing sea ice in situ difficult, expensive, and potentially dangerous - both for personnel and equipment. Such logistical challenges are heightened during the initial growth and final melt of sea ice, which are particularly interesting study periods. Also, the heterogeneous nature of sea ice, with important parameters varying over submetre scales (Miller et al., 2015) and responding to subdiurnal fluctuations in air temperature, make conducting process studies in the field difficult. These logistical and scientific difficulties motivate the use of laboratory-grown sea ice to bridge observational gaps.

Existing laboratory facilities vary widely, tending to be designed with specific observations in mind and circumventing specific constraints. The lengths of sea-ice tanks vary from tens of metres (e.g. Rysgaard et al., 2014; Cottier et al., 1999) to tens of centimetres (e.g. Eide and Martin, 1975; Nomura et al., 2006). Larger tanks minimise edge effects and allow for more samples to be taken. Smaller tanks are cheaper to build and run and have better controlled boundary conditions. The cooling methods used to form artificial sea ice range from cold plates (Cox and Weeks, 1975; Eide and Martin, 1975; Wettlaufer et al., 1997) through the controlled atmosphere of a cold room (Tison et al., 2002; Style and Worster, 2009; Naumann et al., 2012; Marks et al., 2017) to the outdoors (Rysgaard et al., 2014; Hare et al., 2013). Cold plates provide the tightest control over the upper boundary condition but preclude the study of many processes at the upper interface, because the experimental system has no atmosphere. There are few chambers in the literature with atmospheres enclosed in a headspace (Nomura et al., 2006), possibly because, as noted by Loose et al. (2011), the temperature of an enclosed headspace tends to be much warmer than the cold room in which the experimental system is housed. Most facilities use the entire cold room as an atmosphere. Tanks have been made of glass (Naumann et al., 2012), plastic (Loose et al., 2009; Eide and Martin, 1975), stainless steel (Shaw et al., 2011), and concrete (Rysgaard et al., 2014). Of these, glass has the advantage of excellent chemical inertness, while steel, concrete, and plastic are cheaper and can be more robust. Glass and plastic allow the sea ice to be observed through the tank sides. Lighting may be placed above a sea-ice tank to provide illumination for radiative transfer experiments (Perovich and Grenfell, 1981; Marks et al., 2017). Finally, sea-ice tanks are either cuboid (e.g. Tison et al., 2002; Naumann et al., 2012; Rysgaard et al., 2014; Nomura et al., 2006; Wettlaufer et al., 1997), cylindrical (e.g. Cox and Weeks, 1975; Perovich and Grenfell, 1981; Loose et al., 2009; Marks et al., 2017), or quasi two-dimensional Hele-Shaw cells (Eide and Martin, 1975; Middleton et al., 2016). Wave generation is easier in a cuboid tank, whereas cylindrical tanks will have simpler edge effects. Hele-Shaw cells allow for visualisation of the internal sea-ice structure.

There are several examples of sea-ice tanks having proved effective in generating and testing hypotheses. As an example, much of our understanding of gravity drainage was produced or refined using sea-ice tank experiments. Laboratory studies traced brine (Cox and Weeks, 1975; Eide and Martin, 1975), visualised brine channels (Niedrauer and Martin, 1979), and provided idealised conditions to evaluate models (Wettlaufer et al., 1997; Notz, 2005) and measurement techniques (Notz et al., 2005). The understanding, qualitative and quantitative, of processes developed by these studies has led to the development of physically faithful, precise gravity drainage parameterisations (Wells et al., 2011; Griewank and Notz, 2013; Turner et al., 2013; Rees Jones and Worster, 2014). Sea-ice tanks also played a key role in developing models of gas transport in and around sea ice. Laboratory experiments have been used to estimate the magnitude of gas fluxes (Nomura et al., 2006), investigate the processes by which gases are transported (Loose et al., 2009; Kotovitch et al., 2016; Shaw et al., 2011), and to investigate ocean-atmosphere gas fluxes through breaks in sea-ice cover (Loose et al., 2011; Lovely et al., 2015). For both gas fluxes and gravity drainage, progress was made by integrating laboratory studies with field measurements and modelling (e.g. Zhou et al., 2014; Notz and Worster, 2008). Laboratory sea ice has helped develop our understanding of radiative transfer in sea ice (Perovich and Grenfell, 1981; Marks et al., 2017), frost flower formation (Style and Worster, 2009; Perovich and Richter-Menge, 1994), the thermodynamics of grease ice and nilas (Naumann et al., 2012; De La Rosa et al., 2011), and many other fields.

Here, we describe and characterise the Roland von Glasow Air-Sea-Ice Chamber (RvG-ASIC) to aid future users when planning experiments. We first describe the facility, the instrumentation available, and typical protocols used to grow artificial sea ice (Sect. 2). Next, we characterise the air exchange rate of the chamber with the outside, the mixing rate of the tank, and the variability of the light field - important 
technical metrics for designing and interpreting experiments (Sect. 3.1). We then evaluate how similar our sea ice is to natural sea ice by comparing our experimental sea ice to natural sea ice for three key parameters: the extinction of photosynthetically active radiation, the bulk salinity, and the growth rate (Sect. 3.2).

\section{Facility description}

\subsection{Infrastructure}

Our artificial ocean is contained in a cuboid, open-topped, glass tank (Fig. 1). The internal footprint of the tank is $2.35 \mathrm{~m} \times 1.35 \mathrm{~m}$, and the depth of the tank is $1.17 \mathrm{~m}$. The glass is $25 \mathrm{~mm}$ thick, joined at the edges with silicone resin, and reinforced with a metal bracketing bar. A smaller cuboid glass tank $(0.5 \mathrm{~m} \times 0.4 \mathrm{~m}$ footprint, $1.12 \mathrm{~m}$ depth, $12 \mathrm{~mm}$ wall thickness) is joined to the main tank, connected by four $100 \mathrm{~mm}$ holes (Fig. 1). This side tank - capped with a lid - is never allowed to freeze over entirely and so provides a path for sample lines into the ocean, a path for cables that does not interfere with the sea-ice-atmosphere interface, and a free path for water displaced by volume expansion upon freezing. The main and side tanks have been insulated using $10 \mathrm{~cm}$ of Dow 500A Floormate foam $\left(0.035 \mathrm{~W} \mathrm{~m}^{-1} \mathrm{~K}^{-1}\right.$ thermal conductivity) and $10 \mathrm{~cm}$ of foil-backed loft insulation. Heating film ( $12 \mathrm{~V}$, maximum output $\left.220 \mathrm{~W} \mathrm{~m}^{-2}\right)$ was placed outside of the glass and within the insulation. The heating pads and insulation ensure that the dominant cooling of our experimental system is at the exposed upper interface rather than through the tank sides. They also prevent sea ice attaching to our tank walls so that it remains free floating. Two to four pumps (TUNZE stream 6125, maximum flow rate of $12000 \mathrm{~L} \mathrm{~h}^{-1}$ ) are placed in the main and side tanks to mix the ocean. The pumps are fixed to the tank walls using magnets and can be positioned as needed.

A lighting rack sits at $1.3 \mathrm{~m}$ above the tank base (Fig. 1). Eight UV-B lamps (Philips broadband TL $100 \mathrm{~W}$ ), eight UVA lamps (Philips Cleo performance $100 \mathrm{~W}$ ), and eight visible LED strips (Fluence solar max) are spaced evenly over the length of the tank. The visible lights can be individually dimmed from $100 \%$ to $10 \%$ of the full output. The LED, UV-A, and UV-B spectra are shown in Fig. 2.

The tank and lights are housed in a cold room with a temperature range of -55 to $+30^{\circ} \mathrm{C}$. The external footprint of the cold room is $4.32 \mathrm{~m} \times 4.32 \mathrm{~m}$. The external height is $3.15 \mathrm{~m}$ and the internal height is $2.85 \mathrm{~m}$ (Fig. 3). The internal surfaces of the cold room are stainless steel. Six fans recirculate air within the cold room via a compressor. The cold room is connected to the outside by double doors, with six $10 \mathrm{~cm}$ holes for sample, power, and data lines; one drainage hole; and one ventilation hole. All of these can be closed, and the sample, power, and data lines can be fed in through gas-tight
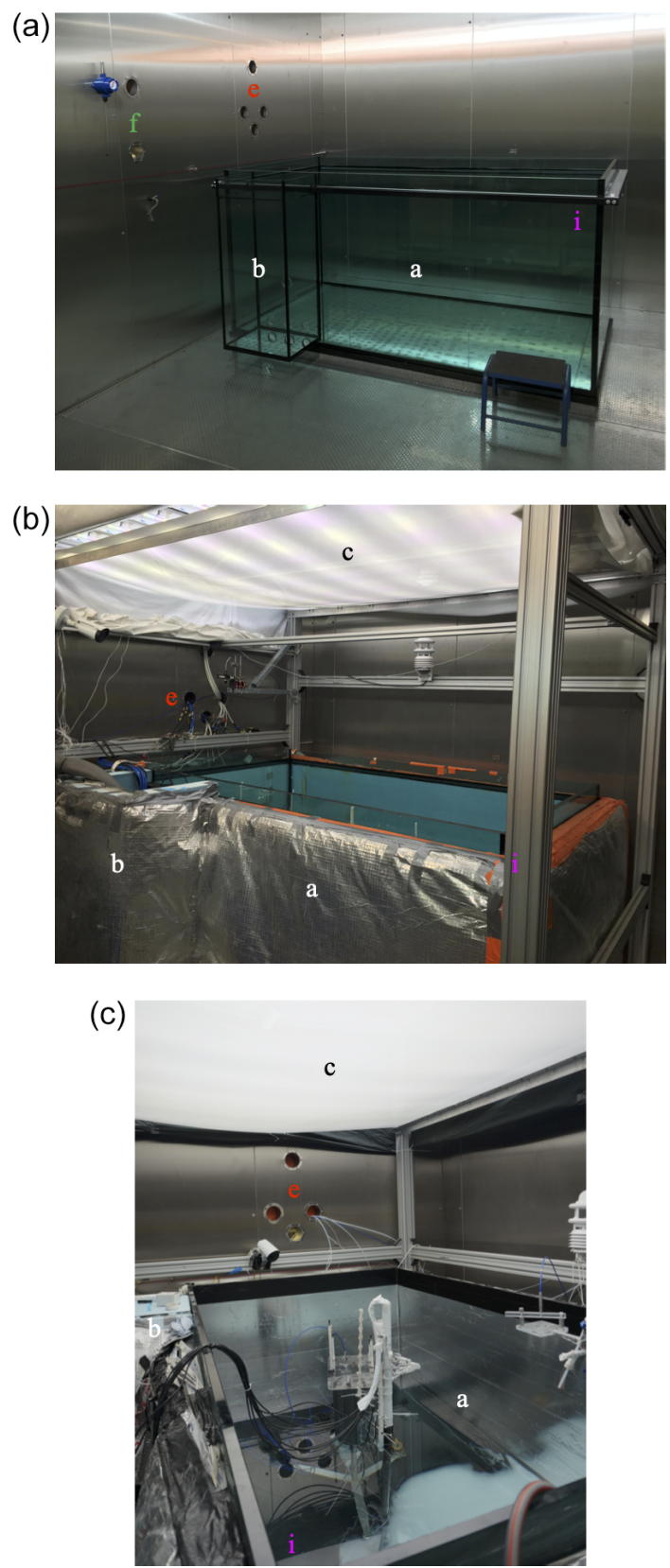

Figure 1. The tank just after installation (a), with all the main features in place (b), and set up for experiments with visible lighting (c). The labels are consistent with Fig. 3, indicating: a the main tank, b the side tank, c the lights, e atmosphere sample lines and cables, f ocean sample lines and cables, and $i$ the $(0,0)$ position of our sampling coordinate system.

Roxtec ports. The cold room is controlled by a Eurotherm nanodac control panel.

The cold room is located in an external laboratory. The control boxes for instrumentation, heating, pumps, cameras, and valves are all situated adjacent to the cold room. Instruments $\log$ to an Envidas Ultimate acquisition system software for continuous monitoring of the data. Mains or 


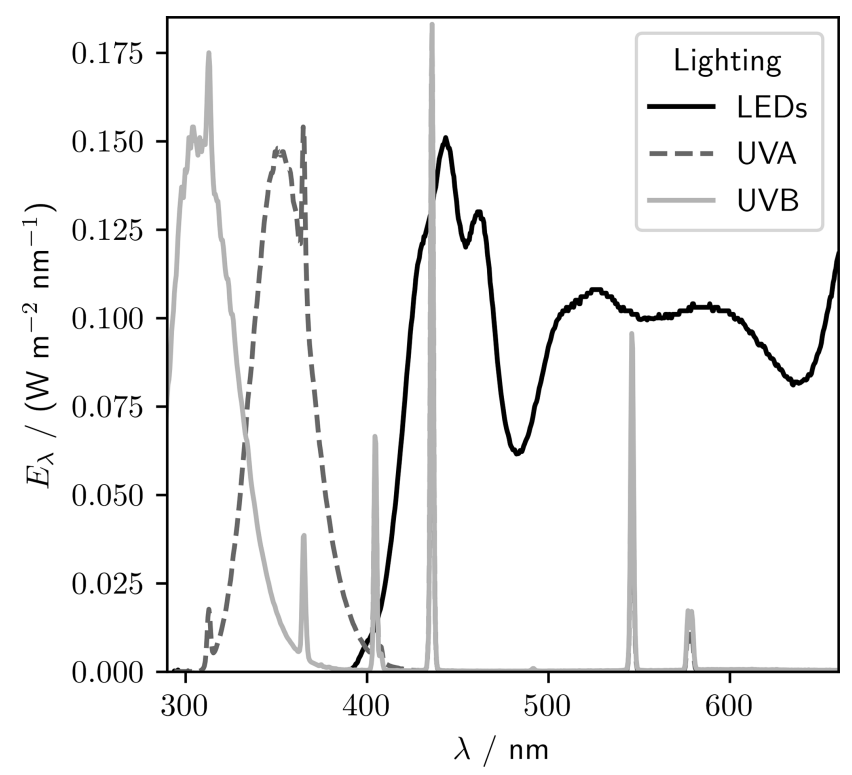

Figure 2. Spectral irradiance, $E_{\lambda}$, for the lights in the RvG-ASIC at $1 \mathrm{~m}$ height and room temperature.

18.2 M $\Omega$ water supplies (Centra R 200) are available for filling the tank.

We use "chamber" to describe the experimental system. When the tank is exposed to the entire cold room, as for all the experiments presented here, the cold room is the chamber.

\subsection{Instrumentation}

The RvG-ASIC has a suite of instruments for carrying out measurements of the experimental ocean, sea ice, and atmosphere (Table 1).

\subsubsection{Ocean}

The ocean temperature, $\theta_{\mathrm{o}}$, and conductivity, $\gamma_{\mathrm{o}}$, can be monitored by a temperature and conductivity recorder (Sea-Bird MicroCAT SBE 37SIP or Valeport mini CT). $\theta_{0}$ and $\gamma_{0}$ measurements are converted to a salinity, $S_{\mathrm{o}}\left(\mathrm{g} \mathrm{kg}^{-1}\right)$, using either the GSW toolbox (McDougall and Barker, 2011) for representative ocean salt composition or using equations presented in Naumann et al. (2012) for pure $\mathrm{NaCl}$. A sonar (Aquascat 1000R) measures the position of the waterline at the start of the experiment and the position of the base of the sea ice throughout the experiment. We use the GSW toolbox to calculate the speed of sound for a given $S_{\mathrm{o}}$ and $\theta_{\mathrm{o}}$ and scale the raw sonar output to produce an accurate distance measurement. We can deploy a Liquicel $1.7 \times 5.5$ MiniModule in our ocean coupled to a LGR GGA-30r-EP OA-ICOS laser spectrometer to measure the concentration of dissolved $\mathrm{CH}_{4}$ and $\mathrm{CO}_{2}$ in the ocean without removing water from the experimental system.

\subsubsection{Sea ice}

Temperature, $\theta$, profiles through the ocean and sea ice are measured using chains of digital thermometers (Table 1). These have a resolution of $\frac{1}{16}^{\circ} \mathrm{C}$ and are calibrated against $\theta$ measured by the Sea-Bird 37SIP before each run while they sit in well-mixed water. The chains have 1 to $8 \mathrm{~cm}$ resolution and are 10 to $80 \mathrm{~cm}$ long. Wireharps (Notz et al., 2005; Notz and Worster, 2008) are used to measure a liquid fraction profile, $\phi$, through the sea ice using

$\phi=\frac{\gamma_{0} R_{0}}{\gamma_{t}\left(\theta, S_{\mathrm{br}}\right) R_{t}}$,

where $R$ is the resistance between a given wire pair, $\gamma$ is the conductivity of the solution between the wire pairs, and the subscripts 0 and $t$ indicate the point in time at which the seaice front passes a wire pair and some later point in time. We calculate the bulk sea-ice salinity, $S_{\mathrm{si}}\left(\mathrm{g} \mathrm{kg}^{-1}\right)$, using

$S_{\mathrm{si}}=\phi S_{\mathrm{br}}(\theta)$

where $S_{\mathrm{br}}(\theta)$ is a the brine salinity. $S_{\mathrm{br}}(\theta)$ is retrieved from the third-order polynomial presented in Vancoppenolle et al. (2019) (for natural seawater composition)

$$
\begin{aligned}
S_{\mathrm{br}} /\left(\mathrm{g} \mathrm{kg}^{-1}\right) & =-18.7\left(\theta /{ }^{\circ} \mathrm{C}\right)-0.519\left(\theta /{ }^{\circ} \mathrm{C}\right)^{2} \\
& -0.00535\left(\theta /{ }^{\circ} \mathrm{C}\right)^{3}
\end{aligned}
$$

or Rees Jones and Worster (2014) (for $\mathrm{NaCl}$, fit to the data of Weast, 1971),

$$
\begin{aligned}
S_{\mathrm{br}} /\left(\mathrm{g} \mathrm{kg}^{-1}\right) & =-17.6\left(\theta /{ }^{\circ} \mathrm{C}\right)-0.389\left(\theta /{ }^{\circ} \mathrm{C}\right)^{2} \\
& -0.00362\left(\theta /{ }^{\circ} \mathrm{C}\right)^{3} .
\end{aligned}
$$

Our version of the wireharps use two alternating current frequencies, $2 \mathrm{kHz}$ (as used in Notz et al., 2005) and $16 \mathrm{kHz}$. When using the $2 \mathrm{kHz}$ channel, we calculated $\frac{\gamma_{0}}{\gamma_{t}\left(\theta, S_{\text {br }}\right)}$ following Notz et al. (2005). When using the $16 \mathrm{kHz}$ channel, we presume that the electronic double layers driving the conductivity changes are not present and so take $\frac{\gamma_{0}}{\gamma_{t}\left(\theta, S_{\mathrm{br}}\right)}=1$. We have also deployed fibre optics and photodiode light sensors (Hof, 2019, Table 1) in the sea ice and ocean. Fibre optics can be connected to a spectrometer outside of the cold room (Ocean Optics USB2000+). The light sensors consist of photodiodes, waterproofed in resin, measuring in the blue, green, red, and clear. The wavelength range integrated by the photodiodes is, to a good approximation, 400 to $700 \mathrm{~nm}$. The response of the photodiodes is negligible to light with wavelengths shorter than $400 \mathrm{~nm}$. At wavelengths above $700 \mathrm{~nm}$, the response is generally less than $10 \%$ of the maximum response. Diffusing glass plates sit atop the photodiodes to increase the angle of incidence at which light reaches the diodes. The data sheet for the photodiodes is given in the Supplement. 

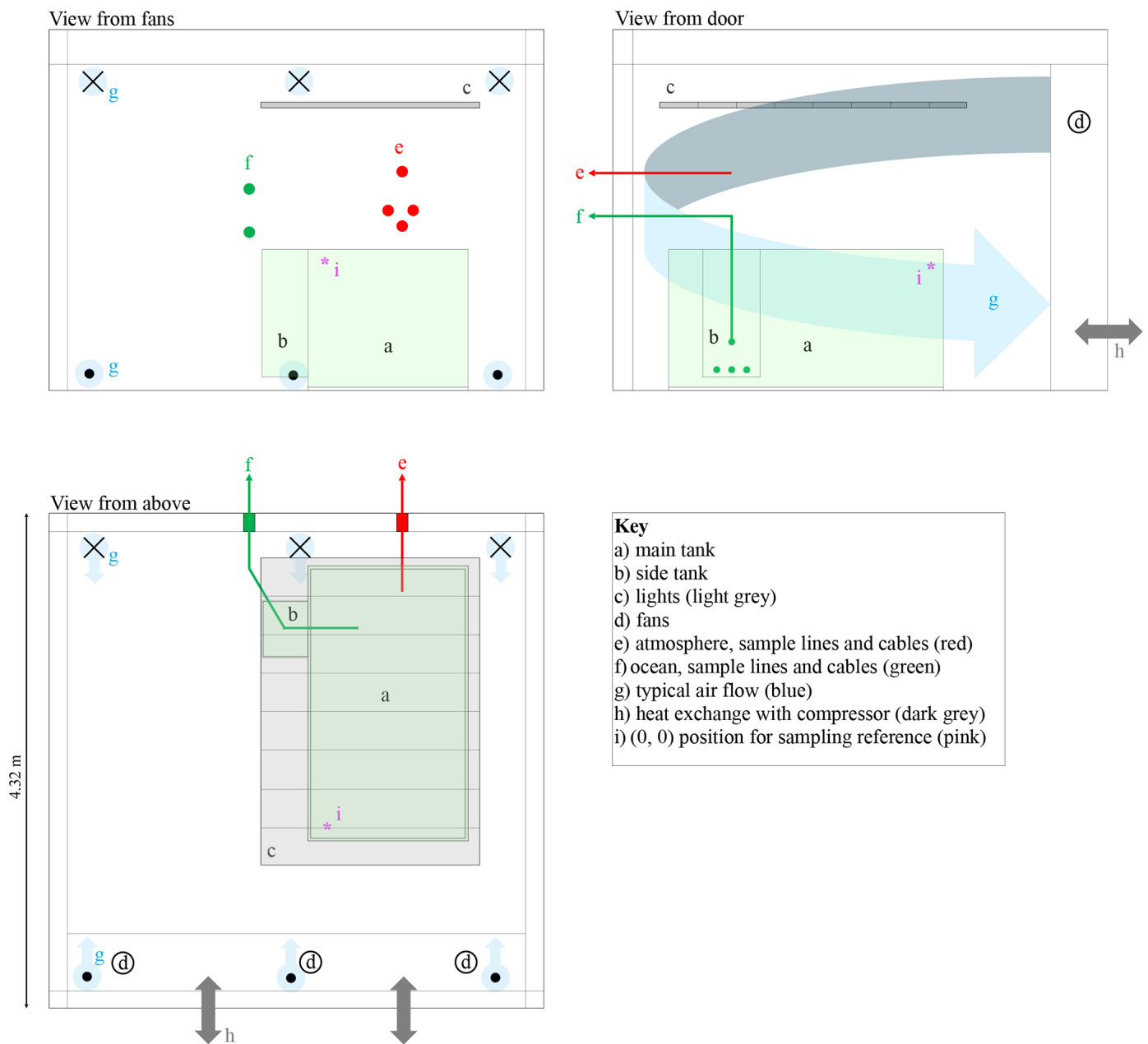

\section{Key}

a) main tank

b) side tank

c) lights (light grey)

d) fans

e) atmosphere, sample lines and cables (red)

f) ocean, sample lines and cables (green)

g) typical air flow (blue)

h) heat exchange with compressor (dark grey)

i) $(0,0)$ position for sampling reference (pink)

Figure 3. Scaled schematic diagram of the cold room. The three panels show orthogonal views from different vantage points. Crosses and dots indicate air flow away from and towards the viewer, respectively. The lights, shown in grey, are made up of eight sets of visible, UV-A, and UV-B triplets. The main and side tanks are pale green.

Table 1. Instruments that are generally available in the RvG-ASIC.

\begin{tabular}{|c|c|c|}
\hline Instrument & Parameter & Experiment compartment \\
\hline Sea-Bird MicroCAT SBE 37-SIP & conductivity, temperature & ocean \\
\hline DS18B20U digital thermometer & temperature & sea ice and ocean \\
\hline Wireharp & liquid fraction & sea ice \\
\hline TCS3472 photodiodes & irradiance, 400 to $700 \mathrm{~nm}$ & sea ice, ocean, and atmosphere \\
\hline Ocean Optics spectrometer (USB2000+) & spectral irradiance & sea ice, ocean, and atmosphere \\
\hline Metcon spectral radiometer & wavelength-resolved 280 to $650 \mathrm{~nm}$ actinic flux & sea ice, ocean, and atmosphere \\
\hline LGR GGA-30r-EP & $\mathrm{CO}_{2}$ and $\mathrm{CH}_{4}$ mole fraction & atmosphere and equilibrated air \\
\hline LGR FGGA & $\mathrm{CO}_{2}$ and $\mathrm{CH}_{4}$ mole fraction & atmosphere and equilibrated air \\
\hline Teledyne T200UP & $\mathrm{NO} / \mathrm{NO}_{2} / \mathrm{NO}_{x}$ mole fractions & atmosphere \\
\hline Teledyne T200U & $\mathrm{NO} / \mathrm{NO}_{y}$ mole fractions & atmosphere \\
\hline Teledyne T400 & $\mathrm{O}_{3}$ mole fraction & atmosphere \\
\hline Teledyne T700U & dynamic dilution calibrator with ozone generator & \\
\hline Teledyne $\mathrm{T} 701 \mathrm{H}$ & zero air generator & \\
\hline WS600-UMB & temperature, wind speed, humidity & atmosphere \\
\hline Camsecure, underwater camera & video & ocean \\
\hline 4K HD video camera & video & atmosphere \\
\hline
\end{tabular}




\subsubsection{Atmosphere}

The temperature, wind speed, and relative humidity of our atmosphere are measured using a weather station (WS600UMB). Two Los Gatos Research (LGR) greenhouse gas analysers measure $\mathrm{CO}_{2}, \mathrm{CH}_{4}$, and $\mathrm{H}_{2} \mathrm{O}$ mole fractions in the atmosphere and can also analyse the air stream of the Liquicel equilibrator (Table 1). A Teledyne T200UP measures NO and $\mathrm{NO}_{x}$ and a T200U measures $\mathrm{NO}$ and $\mathrm{NO}_{y}$. A Teledyne T400 measures ozone. There is also a zero air generator (T701 $\mathrm{H}$, Teledyne) and a T700U dynamic dilution calibrator with ozone generator.

\subsection{Experimental protocols}

Protocols vary widely between experiments. Here, we provide a typical protocol to help future users visualise the facility and plan experiments.

\subsubsection{Set-up phase}

We set up instrumentation in a dry, clean tank. Sea-ice instrumentation is attached to poles that are free to rise in the vertical as sea ice grows and floats. Ocean and atmosphere instrumentation and sample lines are mounted in a fixed position. The nature of the experiment will determine the state of the tank sides and base. For optical experiments (Sect. 3.2.1), the tank's inner surfaces should be covered to simplify the light field. We use mirrored sides and a matt black base to approximate infinite lateral boundary conditions and a non-reflective ocean (Fig. 1).

To fill the tank, we add $100 \mathrm{~kg}$ of salt and mix this with tap or $18.2 \mathrm{M} \Omega$ water. The salt can be pure $\mathrm{NaCl}$ (used for Sect. 3.1.2 and 3.2.1) or a natural sea salt composition (Tropic Marin sea salt classic, used for Sect. 3.2.2). The tank takes around $18 \mathrm{~h}$ to fill with de-ionised water or a few hours from the tap, and $100 \mathrm{~kg}$ of salt dissolves in a few hours under vigorous circulation by the pumps. Alternatively, real sea water can be delivered to the tank. Filling the tank to $1 \mathrm{~m}$ gives an ocean volume of around $3.2 \mathrm{~m}^{3}$. Once the tank is full, we begin to cool the water. The tank surface can be covered at this stage to reduce evaporation. With an atmospheric temperature of $-20^{\circ} \mathrm{C}$, and an uncovered tank, the temperature of $3.2 \mathrm{~m}^{3}$ of ocean drops by around $1{ }^{\circ} \mathrm{C}$ every $4 \mathrm{~h}$. If the experiment requires an isolated cold room atmosphere, the cold room is sealed at this stage. Sea-ice growth can be initialised by continuing to cool under constant temperature and vigorous circulation. Alternatively, once the water is within a few tenths of a degree of its freezing point, turning the pumps to a low setting, or off, initialises sea-ice growth within a few minutes. As a rule of thumb, it takes one full week to go from a dry tank to first sea ice.

\subsubsection{Growth phase}

The water circulation rate and the atmospheric temperature determine the nature of the sea ice (Naumann et al., 2012). Nilas will grow in quiescent water. In circulating water, a layer of grease ice will form that subsequently consolidates. When the growth temperature is less than $-25^{\circ} \mathrm{C}$, frost flowers form on the sea-ice surface (Fig. 4). By running the heating pads between the main tank and insulation, we are able to maintain free-floating sea ice to $20 \mathrm{~cm}$ thickness with no visible water gap at the tank sides. We have verified that the sea ice is free-floating in several experimental runs by gently pressing the corner of the sea ice and noting that it bobs. With no, or insufficient, side heating, the sea ice attaches to the tank sides and the surface floods (e.g. Rysgaard et al., 2014), resulting in a shiny, liquid surface layer. Sea ice, fast to the tank walls, has been grown up to $25 \mathrm{~cm}$ thickness and could potentially be grown thicker. With insufficient side heating and insulation, the ocean tends to supercool (Fig. 5). When the ocean supercools, ice grows on the tank sides and instruments, causing problems with measurements and potentially damaging equipment. Growth phases typically last for a few days to a few weeks.

\subsubsection{Sampling protocols}

Underlying water may be sampled throughout, providing the volume is replaced. We sample sea ice either by taking cores using a $7.5 \mathrm{~cm}$ diameter Kovacs ice corer or using the procedures outlined by Cottier et al. (1999) to extract sea-ice "slabs". Sea-ice cores have a known bias, particularly problematic in young sea ice, as brine is lost from the permeable sea ice near the ocean interface. The method of Cottier et al. (1999) seeks to minimise this bias by collecting sea-ice samples that are still floating and then freezing the sample and surrounding ocean at $-40^{\circ} \mathrm{C}$ to immobilise the brine before processing the sample. The method of Cottier et al. (1999) becomes difficult and time consuming when sea ice is thicker than around $25 \mathrm{~cm}$ due to limitations of the power tools used to extract the slabs and the weight of the slabs. We cut cores and slabs into discrete vertical profiles using a bandsaw with a precleaned blade at $-25^{\circ} \mathrm{C}$.

\section{Characterisation of experimental system}

We now turn to a characterisation of our experimental system. First, in Sect. 3.1, we quantify several parameters regarding the technical capabilities of the facility: the exchange rate between the chamber and the outside, the mixing rate of the water in the tank, and the variability in the light field. In doing so, we aim at providing valuable information to help plan and interpret future studies. Next, in Sect. 3.2, we present measurements of our experimental sea ice to quantify the extinction of PAR ( $\lambda=400$ to $700 \mathrm{~nm})$, the bulk salinity, and the growth rate of our experimental sea ice. The goal 
(a)

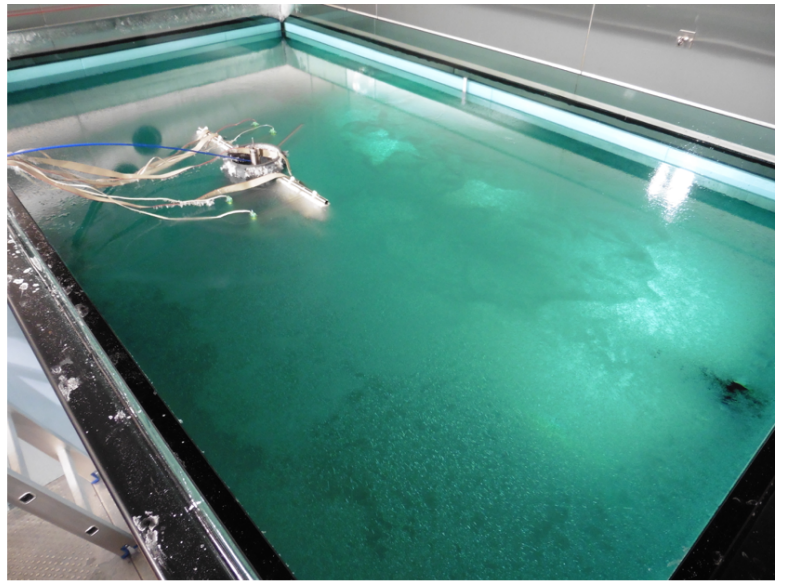

(b)

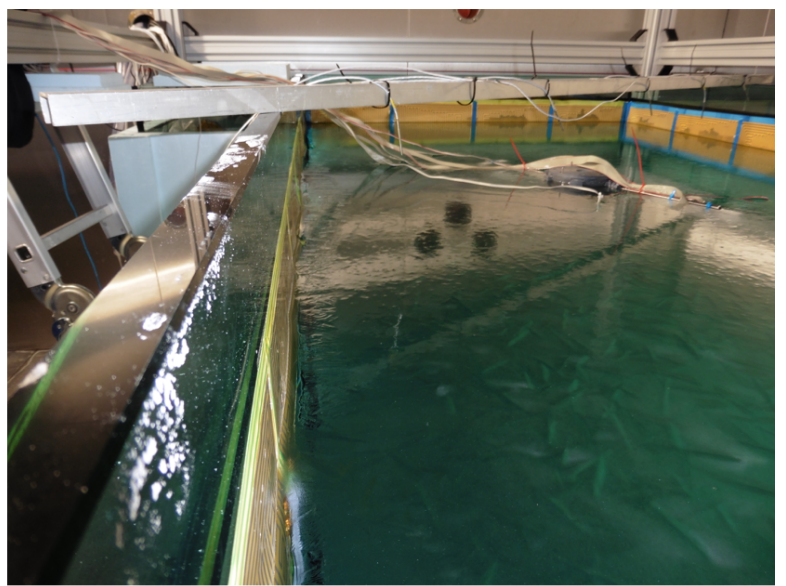

(c)

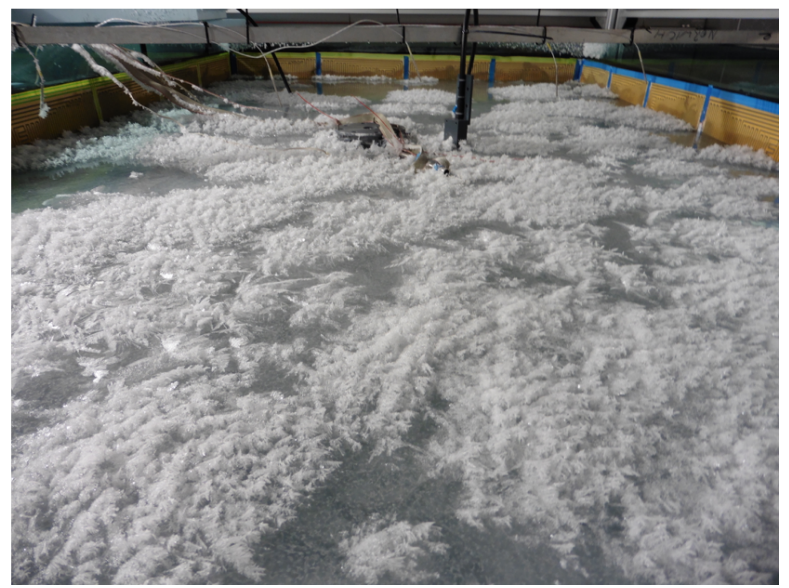

Figure 4. Grease ice (a) grown under pumping, nilas (b) grown in quiescent conditions, and a frost flower field (c) grown in the RvGASIC.

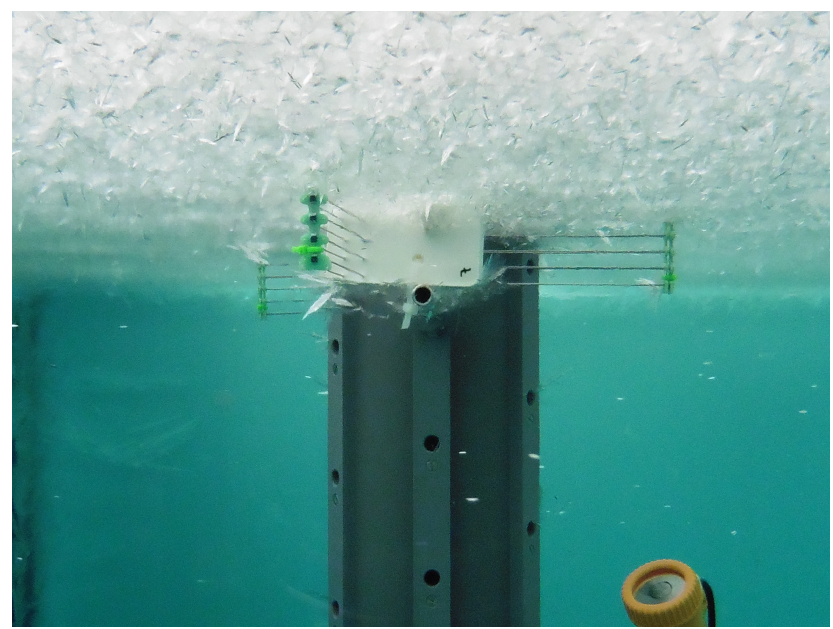

Figure 5. A view of a supercooled ocean. Frazil ice crystals are floating upwards in the water column (white flecks) and have nucleated on wireharps well ahead of the advancing sea-ice-ocean interface.

of this section is to investigate how similar our laboratorygrown sea ice is to natural sea ice with respect to these important characteristics.

\subsection{Technical characterisation}

\subsubsection{Quantifying the cold room air exchange rate}

For most experiments, it is desirable to have the sea-iceatmosphere interface exposed to the bulk air within the cold room. Leaving the atmosphere of the tank uncapped ensures that the temperature of the atmosphere overlying the sea ice is responsive to the cold room atmosphere. When the atmosphere is contained by some headspace, the temperature tends to be much warmer than the cold room (e.g. Loose et al., 2011). Here, we quantify the degree to which the cold room can be sealed from the outside by deriving the air exchange rate coefficient, $k$, and time constant, $\tau_{1}$, of $\mathrm{CH}_{4} \mathrm{ex}$ changing between the cold room to the outside (Fig. 6).

To do so, we sealed the cold room and left the tank dry. We then diluted the chamber air by filling it with $\mathrm{N}_{2}$ gas. We performed two dilutions, the first at around 18:00 LT on 12 February 2019 and the other at around 16:00 LT on 13 February 2019. The $\mathrm{CH}_{4}$ concentration in the chamber, $C_{\text {cham }}$, was monitored using an LGR (GGA type, Table 1), where measured air was returned to the cold room in a closed loop (Fig. 6a and d). The dilution reduced $C_{\text {cham }}$ by around $0.1 \mathrm{ppm}$ in both dilution periods. We stopped the dilution by stopping the $\mathrm{N}_{2}$ flow, at which point the chamber was sealed to the best of our ability. We measured the $\mathrm{CH}_{4}$ concentration in the outer laboratory, $C_{\text {room }}$, throughout using an LGR (FGGA type, Table 1), and we used the difference between $C_{\text {cham }}$ and $C_{\text {room }}$ as the concentration gradient between the chamber and the outside (Fig. $6 \mathrm{~b}$ and e). Before the exper- 

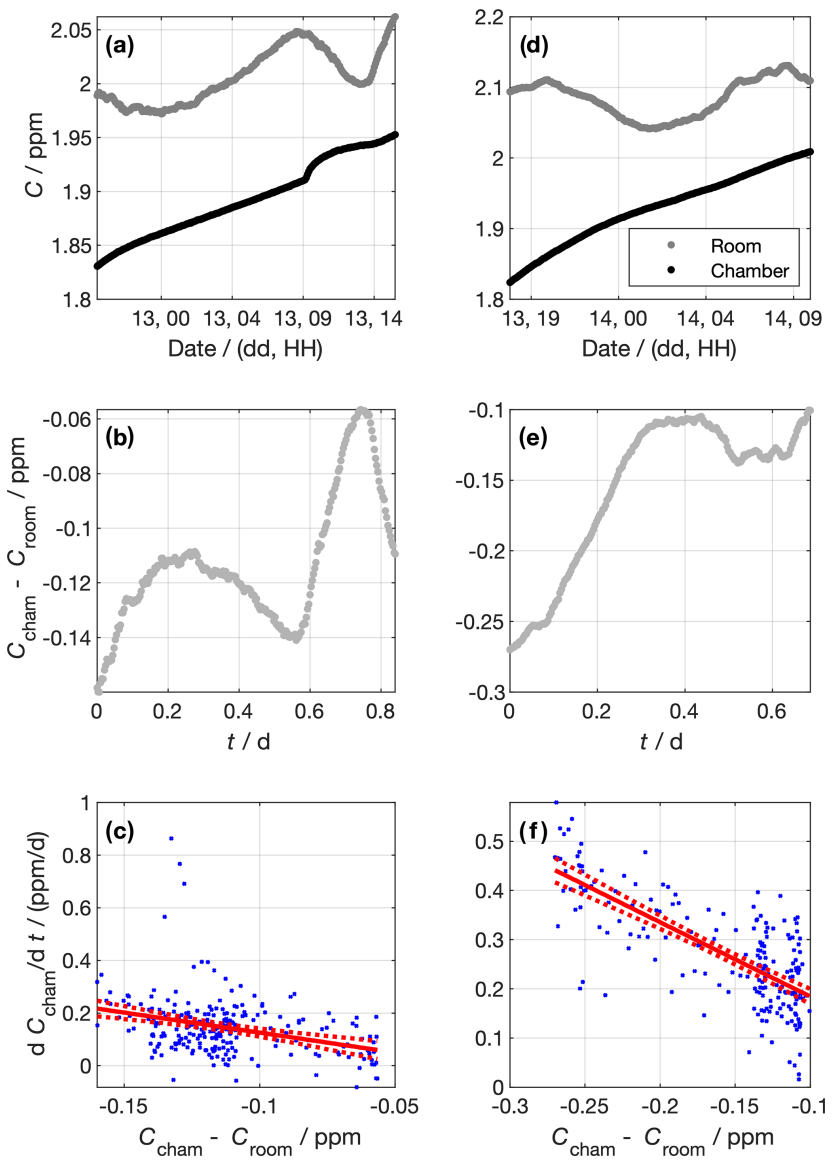

Figure 6. Data from experiments to determine the chamber air exchange rate. Panels (a) to (c) and (d) to (f) show data from the first and second experiments, respectively. The top panels (a and d) show the measured $\mathrm{CH}_{4}$ concentrations in the chamber and the lab outside. Panels (b) and (e) show the concentration difference between the chamber and the lab outside. Panels (c) and (f) show the linear regressions constructed using Eq. (5). Blue dots show individual data points. The red lines show the best fit and $95 \%$ confidence intervals of the linear regression of $\frac{\mathrm{d} C_{\text {cham }}}{\mathrm{d} t}$ against $C_{\text {cham }}-C_{\text {room }}$. The gradient of the linear regression corresponds to the air exchange rate coefficient, $-k$. For the first experiment, $k=(1.5 \pm 0.3) \mathrm{d}^{-1}$, and for the second experiment, $k=(1.5 \pm 0.1) \mathrm{d}^{-1}$.

iment, the two LGR instruments measured the same air for $30 \mathrm{~h}$. The offset between them was $(6.4 \pm 0.2) \mathrm{ppb}$. This offset was added to $C_{\text {room }}$ values to make the measurements from the two LGR instruments consistent. Data were averaged in 5 min bins. We modelled the exchange rate as a first-order process,

$\frac{\mathrm{d} C_{\text {cham }}}{\mathrm{d} t}=-k\left(C_{\text {cham }}-C_{\text {room }}\right)$.

We approximate $\frac{\mathrm{d} C_{\text {cham }}}{\mathrm{d} t}$ for each measurement interval using the difference in $C_{\text {cham }}$ between adjacent data points over the 5 min between those data. Panels c (experiment 1) and $\mathrm{f}$ (experiment 2) of Fig. 6 show the relationship between $\frac{\mathrm{d} C_{\text {cham }}}{\mathrm{d} t}$ and $C_{\text {cham }}-C_{\text {room }}$, as well as the linear fit. We derived $k=(1.5 \pm 0.3) \mathrm{d}^{-1}$ and $k=(1.5 \pm 0.1) \mathrm{d}^{-1}$ for the first and second experiments, respectively. Taking the mean $k$ of the two experiments, the air exchange time constant is then given by

$\tau_{1}=1 / k=(0.66 \pm 0.07) \mathrm{d}$.

The physical interpretation of this $\tau_{1}$ is that the concentration difference between the sealed chamber and the outside will reduce by a factor of $e$ every $(0.66 \pm 0.07) \mathrm{d}$.

\subsubsection{Quantifying the tank mixing rate}

For some experiments, it may be necessary to spike the ocean with a chemical. We may, in such cases, want to know when the water will be well mixed with respect to our spike. Similar to the air exchange rate (Sect. 3.1.1), the degree to which the chemical has mixed can be quantified using a time constant, $\tau_{\mathrm{m}}$. To derive this time constant, we spiked our tank with saturated $\mathrm{NaCl}$ solution by injecting it near the tank base and observed the conductivity of our ocean over time as it mixed under the action of three pumps (Fig. 7). The temperature of the ocean was stable to within $0.02^{\circ} \mathrm{C}$ for the hour time period over which we monitored both spikes, so we expect the salinity to be linearly related to the conductivity. The conductivity of the ocean, $\gamma_{0}$, can then be described by

$\gamma_{\mathrm{o}}(t)=e^{-\frac{t}{\tau_{\mathrm{m}}}}\left(\gamma_{\mathrm{o}}\left(t_{0}\right)-\gamma_{\mathrm{o}, \infty}\right)+\gamma_{\mathrm{o}, \infty}$,

where $\gamma_{0, \infty}$ is the maximum ocean conductivity obtained after the spike and $t_{0}$ is the time of the spike. Fitting an exponential curve to a manually defined spike period for the two runs produces $\tau_{\mathrm{m}}=(4.2 \pm 0.1) \min$ (run 1$)$ and $\tau_{\mathrm{m}}=$ $(4.1 \pm 0.1) \mathrm{min}$ (run 2). We take the mean of the individual experiments to characterise our mixing rate, such that $\tau_{\mathrm{m}}=(4.2 \pm 0.1) \mathrm{min}$. The tank should therefore mix to more than $99 \%$ of the perfectly mixed concentration in less than $30 \mathrm{~min}$.

\subsubsection{Quantifying light-field variability}

Producing a homogeneous light field in a laboratory environment can be difficult, because shading and reflection can cause heterogeneities. The intensity of our lights is also temperature dependent, which is particularly important in the RvG-ASIC given the wide range of experimental temperatures. In this section, we aim to characterise our light field, both in terms of lateral heterogeneity and with changes in temperature.

To assess the spatial variability, we measured PAR (photosynthetically active radiation, $\lambda=400$ to $700 \mathrm{~nm}$ ) across the tank area at $1 \mathrm{~m}$ height (Fig. 8). These measurements were made using a LI-COR LI-1800 spectroradiometer integrated from 400 to $700 \mathrm{~nm}$. The PAR irradiance, $I_{\mathrm{PAR}}$, at $1 \mathrm{~m}$ above the tank base and $25^{\circ} \mathrm{C}$ was generally within $80 \%$ of the 


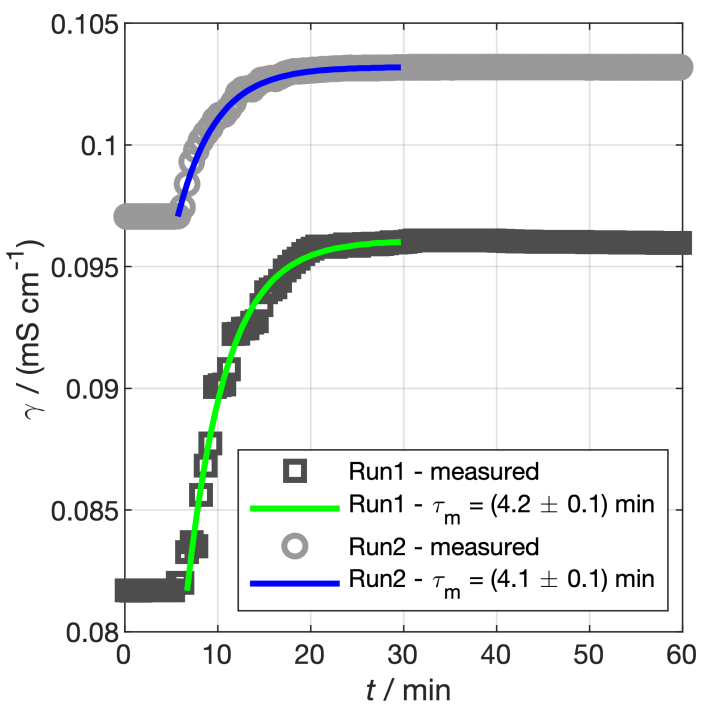

Figure 7. Experiments to determine the mixing time constant of our tank, $\tau_{\mathrm{m}}$. Saturated $\mathrm{NaCl}$ solution was spiked into the tank and mixed under pumping. The conductivity of the bulk water is shown by the grey markers. The coloured lines show the prediction of Eq. (7) using $\tau_{\mathrm{m}}$ fit to the data. In reality, the spike in run 2 was a few hours after run 1, but the times for the two spikes have been matched for ease of comparison.

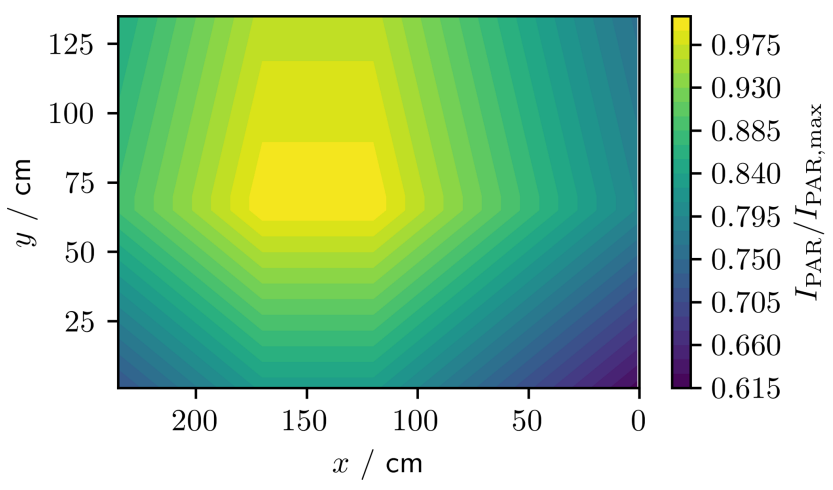

Figure 8. Normalised PAR ( $\lambda=400$ to $700 \mathrm{~nm}$ ) irradiance across the footprint of the tank at $1 \mathrm{~m}$ height. The $(0,0) \mathrm{cm}$ coordinate corresponds to the pink asterisk in Fig. 3.

maximum recorded intensity, $I_{\mathrm{PAR}, \max }$, but dropped as low as $60 \%$ in one corner of the tank.

We measured spectra for UV (UV-A lighting, 320 to $380 \mathrm{~nm}$ ) and PAR (LED lighting, 400 to $700 \mathrm{~nm}$ ) at -30 , $-20,-10$, and $0^{\circ} \mathrm{C}$ using a USB2000+ spectrometer referenced against the Metcon spectral radiometer (Fig. 9). To quantify the temperature sensitivity, we integrated the UV and PAR spectral irradiance over their respective wavelength ranges (320 to $380 \mathrm{~nm}$ and 400 to $700 \mathrm{~nm}$, respectively). The maximum irradiance was $5.6 \mathrm{~W} \mathrm{~m}^{-2}$ for $\mathrm{UV}$ and $26.4 \mathrm{~W} \mathrm{~m}^{-2}$ for PAR, both at $0^{\circ} \mathrm{C}$. The temperature sensitivity of the irradiance was $(0.16 \pm 0.01) \mathrm{W} \mathrm{m}^{-2}{ }^{\circ} \mathrm{C}^{-1}$ for $\mathrm{UV}$ and $(0.028 \pm 0.003) \mathrm{W} \mathrm{m}^{-2}{ }^{\circ} \mathrm{C}^{-1}$ for PAR. The UV-A lights are more strongly temperature dependent, with irradiance dropping by $83 \%$ between 0 and $-30^{\circ} \mathrm{C}$, while PAR irradiance dropped by just $3 \%$.

\subsection{Sea-ice characterisation}

\subsubsection{Determining PAR extinction coefficients in sea ice}

The importance of understanding the sea-ice light field is critical as thinner, fresher, and more transient sea ice becomes more common. Even thin sea ice without snow cover impacts the transmission of PAR to the ocean and has been seen to accumulate algal biomass rapidly within the sea ice (Taskjelle et al., 2016). Photochemical production rates within sea ice are also dependent upon sea-ice optical properties. Irradiation through sea ice has been postulated as a source of OH radicals (King et al., 2005) and as a stressor of diatoms that may lead to iodine production from algae (Küpper et al., 2008).

The rationale for UV-Vis illumination experiments in a controlled sea-ice facility is twofold: first, to allow for experiments investigating the optical properties of sea ice (and potentially other mediums such as snow); second, to allow simple experimental simulations of photochemistry or biology occurring in the sea ice, atmosphere, or ocean. The extinction coefficient, $\kappa$, of PAR in sea ice quantifies the rate of attenuation of PAR with depth. Here, we present measurements of $\kappa$ for sea ice grown in the RvG-ASIC and compare those to previously reported values.

To quantify $\kappa$ in our experimental sea ice, we performed an experiment using visible lighting, measuring a vertical profile of irradiance using eight photodiodes (Sect. 2.2.2). The photodiodes respond dominantly to 400 to $700 \mathrm{~nm}$ light, and our lighting provides irradiance predominantly in the 400 to $700 \mathrm{~nm}$ range, so $\kappa$ as measured by the photodiodes is a good estimate of $\kappa$ for PAR. The tank sides were covered with mirrored tape to approximate infinite lateral boundary conditions, and the tank base was covered with a matt black plastic sheet to approximate no reflection from the ocean. A $3 \mathrm{~mm}$ opal polycarbonate sheet was placed $20 \mathrm{~cm}$ below the light rack to create a diffuse light field, and black curtains were draped between the lights and the tank to prevent reflection off the shiny cold room walls (Fig. 1). We deployed the photodiodes with $2.8 \mathrm{~cm}$ vertical resolution. The sensors were calibrated pre-deployment against the Metcon spectral radiometer. Before each experimental run, while sitting in open water, an additional correction was applied to the in situ sensor output to bring it in line with depth profiles measured using the spectral radiometer. We performed four experiments at growth temperatures of $-10,-20$ (two runs), and $-30^{\circ} \mathrm{C}$ (Table 2). For each run, we present vertical light profiles taken at the end of the growth phase, as well as $\kappa$ calculated by two methods (Fig. 10 and Table 3). Method A 

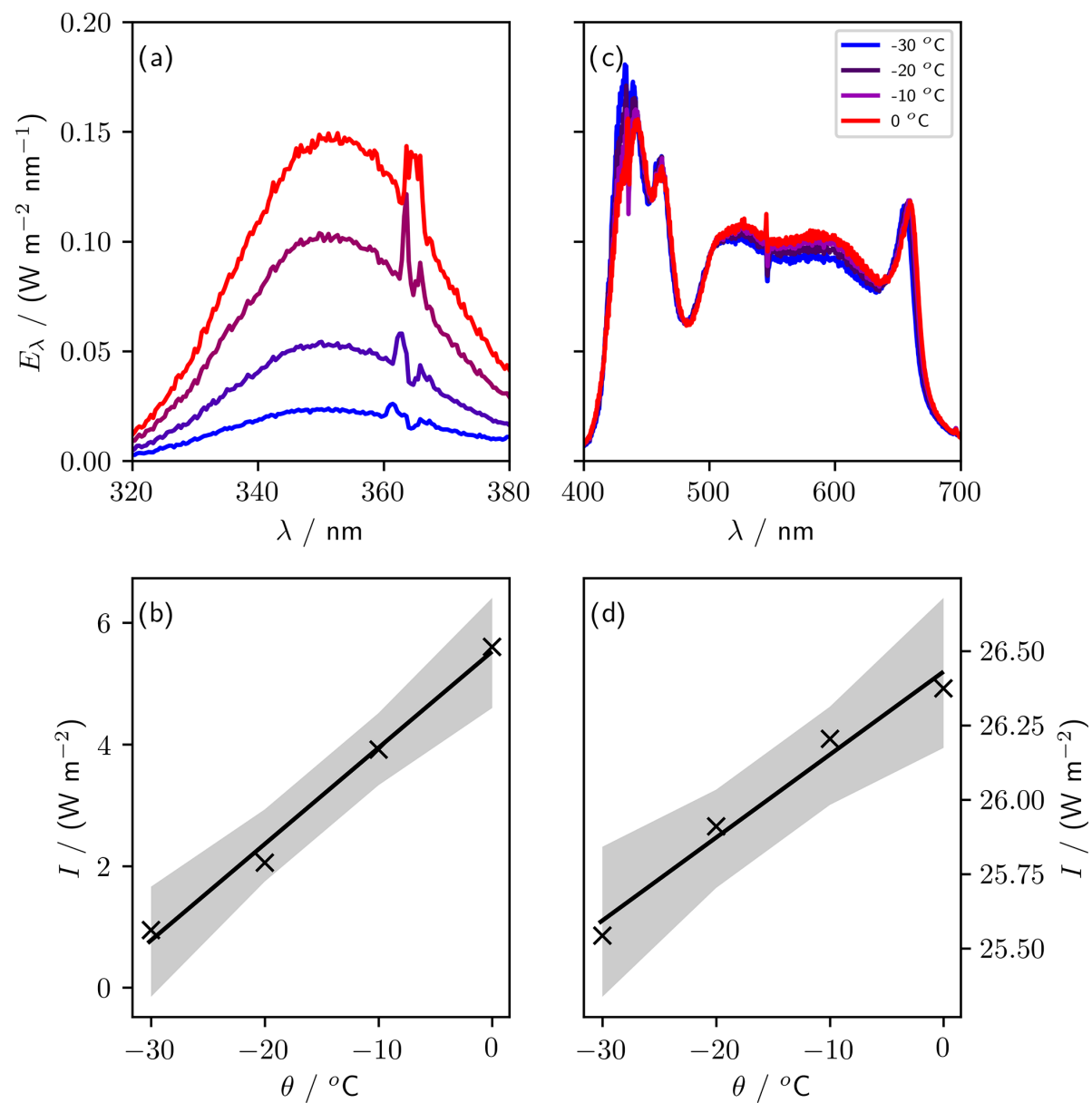

Figure 9. Sensitivity of lights to variations in temperature. Panels (a) (UV) and (c) (PAR) show spectra taken at four temperatures between 0 and $-30^{\circ} \mathrm{C}$. Panels (b) (UV, 320 to $380 \mathrm{~nm}$ ) and (d) (PAR, 400 to $700 \mathrm{~nm}$ ) show the irradiance, $I$ (integrated spectral irradiance over the respective wavelength ranges), at each temperature, $\theta$. The gradient of the regression of $I$ against $\theta$ is $(0.028 \pm 0.003) \mathrm{W} \mathrm{m}^{-2}{ }^{\circ} \mathrm{C}^{-1}$ for PAR and $(0.16 \pm 0.01) \mathrm{W} \mathrm{m}^{-2}{ }^{o} \mathrm{C}^{-1}$ for $\mathrm{UV}$.

(Ehn et al., 2004; Kauko et al., 2017) uses

$\kappa=\ln \left(\left(1-\zeta_{\mathrm{s}}\right) \frac{I(+1.4 \mathrm{~cm})}{I(z)}\right) / z$

The depth, $z$, is chosen to be the shallowest sensor not yet frozen into the sea ice, and spectral reflectance, $\zeta_{\mathrm{s}}$, assumed to be 0.05 . Ehn et al. (2004) measured $\kappa$ ranging from 3.1 to $4.7 \mathrm{~m}^{-1}$ in 24 to $28 \mathrm{~cm}$ thick sea ice (Table 3). Kauko et al. (2017) measured $\kappa$ ranging from 2.9 to $4.7 \mathrm{~m}^{-1}$ in 17 to $27 \mathrm{~cm}$ thick sea ice. For method B, we also calculated $\kappa$ by fitting a linear model to

$\ln \left(I /\left(\mathrm{W} \mathrm{m}^{-2}\right)\right)=-\kappa z+c$,

similar to (Marks et al., 2017). Equation (9) represents a light field decaying exponentially with depth. While methods A and B both provide estimates of $\kappa$, they do so in different ways, with method A using measurements external to the sea ice while method B uses only measurements within the sea ice. Previous studies, compared to our measurements in Table 3, have calculated $\kappa$ by iteratively solving the Dunkle and Bevans (1956) photometric model such that $\kappa$ provides the best fit to measured albedo and transmission (Perovich and Grenfell, 1981) - which we call method C.

Measured light profiles taken at the end of four experiments are shown in Fig. 10. The thickness varied by up to $3 \mathrm{~cm}$ between the four experiments. At the end of the experiments, runs 1 and 2 had six sensors frozen into the sea ice and experiments 3 and 4 had five sensors frozen into the sea ice. The light intensity at $1.4 \mathrm{~cm}$ above the sea ice was between 7.7 and $8.9 \mathrm{~W} \mathrm{~m}^{-2}$ and reduced to between 2.8 and $3.6 \mathrm{~W} \mathrm{~m}^{-2}$ at $18.2 \mathrm{~cm}$ depth. For experiments 1 and 4 , the shallowest frozen sensor measured higher intensity than the sensor above the sea ice, which is a phenomenon that was predicted by Jiang et al. (2005) and that is due to the change in refractive index across the air-ice interface.

Using method A, our calculated $\kappa$ ranges from 3.7 (experiment 4) to $6.1 \mathrm{~m}^{-1}$ (experiment 2). Using method B, our 
Table 2. Overview of experiments used to calculate with PAR extinction coefficients. $\theta_{\text {atm }}$ gives the mean atmospheric temperature during the experiment. $\frac{\psi}{\psi_{\text {sat }}}$ is the mean relative humidity during the experiment, with $\psi$ representing humidity and the subscript sat indicating saturation. $t_{\mathrm{f}}$ gives the duration of the freeze up period. $h_{\mathrm{si}}$ gives the maximum thickness attained, at which point $\kappa$ was measured.

\begin{tabular}{lrcrcl}
\hline Experiment & $\theta_{\mathrm{atm}} /{ }^{\circ} \mathrm{C}$ & $\frac{\psi}{\psi_{\mathrm{sat}}}$ & $t_{\mathrm{f}} / \mathrm{d}$ & $h_{\mathrm{si}} / \mathrm{cm}$ & $\begin{array}{l}\text { Surface } \\
\text { characteristics }\end{array}$ \\
\hline 1 & & & & & Flooded \\
2 & $-18.9 \pm 0.4$ & $0.59 \pm 0.05$ & 6.1 & 18 & Frost flowers \\
3 & $-26.6 \pm 0.9$ & $0.59 \pm 0.03$ & 5.1 & 18 & \\
4 & $-9.2 \pm 0.9$ & $0.52 \pm 0.03$ & 10.1 & 15 & \\
\hline
\end{tabular}

Table 3. Comparison of PAR extinction coefficients ( $\kappa$, wavelength range 400 to $700 \mathrm{~nm}$ ) produced by this work and by different studies.

\begin{tabular}{|c|c|c|c|c|c|}
\hline \multirow[t]{2}{*}{ Experiment } & \multirow[t]{2}{*}{$\theta_{\mathrm{atm}} /{ }^{\circ} \mathrm{C}$} & \multirow[t]{2}{*}{$h_{\mathrm{si}} / \mathrm{cm}$} & \multicolumn{3}{|c|}{$\kappa / \mathrm{m}^{-1}$} \\
\hline & & & A & B & $\mathrm{C}$ \\
\hline This work, Exp. 1 & $-18.9 \pm 0.4$ & 18 & 5.3 & $5.9 \pm 1.9$ & \\
\hline This work, Exp. 2 & $-26.6 \pm 0.9$ & 18 & 6.1 & $4.4 \pm 0.7$ & \\
\hline This work, Exp. 3 & $-9.2 \pm 0.9$ & 15 & 4.1 & $4.5 \pm 1.9$ & \\
\hline This work, Exp. 4 & $-18.0 \pm 0.5$ & 15 & 3.7 & $6.2 \pm 1.7$ & \\
\hline Nice $^{1}$ & -10 to -20 & 17 to 27 & 2.9 to 4.7 & & \\
\hline Santala Bay, Finland ${ }^{2}$ & $<-5$ to 5 & 24 to 28 & 3.1 to 4.7 & & \\
\hline Laboratory $^{3}$ & -10 & 28 & & & 2.5 \\
\hline Laboratory $^{3}$ & -30 & 28 & & & 3 \\
\hline Laboratory 4 & -15 & 40 & & 3 to 10 & \\
\hline
\end{tabular}

calculated $\kappa$ ranges from 4.4 (experiment 2) to $6.2 \mathrm{~m}^{-1}$ (experiment 4). For both methods, the range of $\kappa$ observed in our tank overlaps with the range of $\kappa$ observed previously for thin sea ice. These results build confidence that the RvGASIC is a useful tool for future biological or photochemical experiments in young sea ice and validate this particular experimental setup for experiments involving visible light.

\subsubsection{Estimating sea-ice bulk salinity}

Bulk salinity is a sea-ice state variable that, when measured alongside temperature, can allow for estimation of the seaice liquid fraction. Growing sea ice desalinates rapidly by gravity drainage (Notz and Worster, 2008). The bulk salinity of natural, young sea ice has been measured using cores (Weeks and Lee, 1962) and wireharps (Notz and Worster, 2008). Weeks and Lee (1962) sampled young sea ice in North Star Bay, Greenland, in growing sea ice between 5 and $23 \mathrm{~cm}$ thick. Salinities ranged from around 5 to $20 \mathrm{~g} \mathrm{~kg}^{-1}$ vertically with mean salinities decreasing from $20 \mathrm{~g} \mathrm{~kg}^{-1}$ early in the growth to around $10 \mathrm{~g} \mathrm{~kg}^{-1}$ after $10 \mathrm{~d}$. Notz and Worster (2008) cut a hole in Arctic sea ice and measured the salinity profile, in situ, as it refroze up to $17 \mathrm{~cm}$ thickness (the depth range of their instrument). Over two experiments, they measured bulk salinities ranging from around $35 \mathrm{~g} \mathrm{~kg}^{-1}$ at the sea-ice-ocean interface to around $4 \mathrm{~g} \mathrm{~kg}^{-1}$ in the interior. Mean salinities decreased from around 35 towards $10 \mathrm{~g} \mathrm{~kg}^{-1}$ (experiment 1) and around $15 \mathrm{~g} \mathrm{~kg}^{-1}$ (experiment 2). Here, we present bulk salinities for sea ice grown in the RvG-ASIC, comparing it to the range of salinities observed in nature. Quantifying the vertical bulk salinity profile in sea-ice cores - the most common sea-ice sampling methodology - is difficult due to the known bias during coring of brine loss and bulk salinity underestimation. Several other methodologies have been proposed. Cottier et al. (1999) present a destructive sampling methodology that attempts to prevent brine loss upon sampling (Sect. 2.3.3). Notz et al. (2005) present instrumentation, called a wireharp, to quantify the in situ bulk salinity profile. Several groups have presented gravity drainage parameterisations that quantify the bulk salinity profile during sea-ice growth (Griewank and Notz, 2013; Rees Jones and Worster, 2014; Cox and Weeks, 1988; Vancoppenolle et al., 2010; Turner et al., 2013; Jeffery et al., 2011), noting that gravity drainage is the dominant process redistributing salt in growing sea ice (Notz and Worster, 2009).

We performed two sea-ice growth experiments in the RvGASIC and estimated the sea-ice salinity by (1) constructing a 

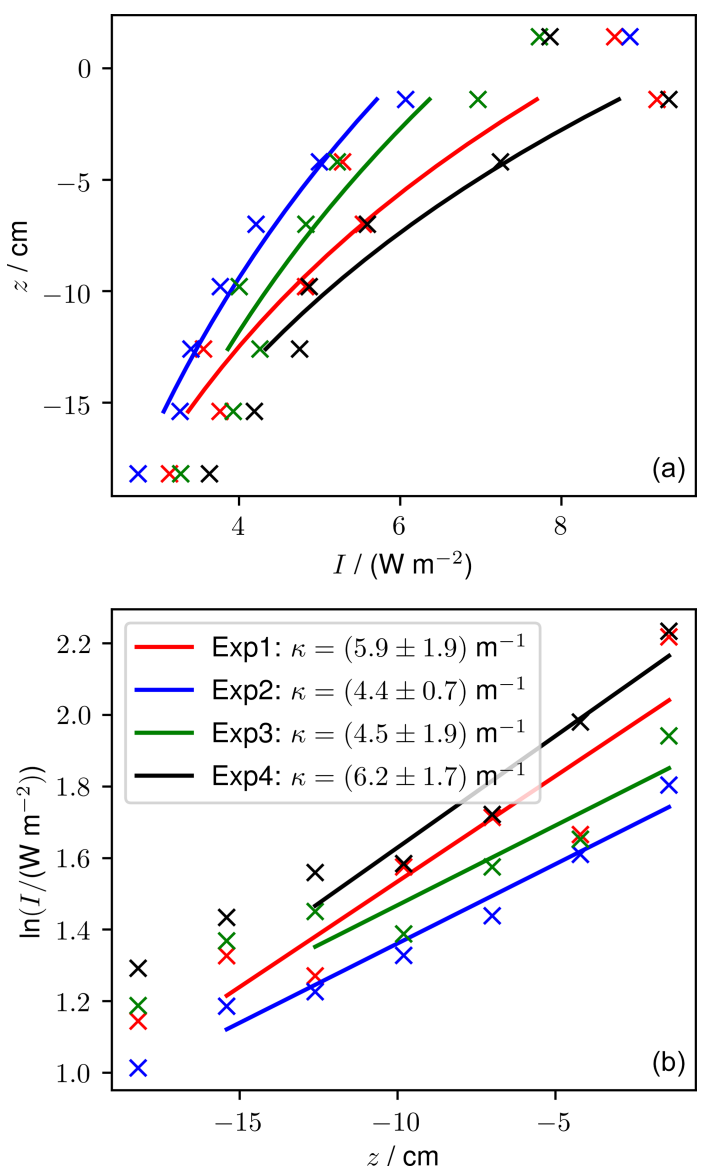

Figure 10. Irradiance profiles (a) and linear regressions of $\ln \left(I / \mathrm{W} \mathrm{m}^{-2}\right)$ vs. $z$ (b) used to produce extinction coefficients (Eqs. 8 and 9) from the final profile of the freezing period. The legend in (b) gives the extinction coefficient for a given profile with 1 standard error.

salt and mass budget, (2) taking sea-ice cores, (3) taking seaice slabs (Cottier et al., 1999), (4) using a wireharp (Notz et al., 2005), and (5) using the Griewank and Notz (2013) gravity drainage parameterisation. Our artificial ocean was composed of Tropic Marin sea salt and deionised water such that $S_{\mathrm{o}}=(31.3 \pm 0.1) \mathrm{g} \mathrm{kg}^{-1}$. We grew free-floating sea ice to $(11.0 \pm 0.9) \mathrm{cm}$ (run 1) and $(16.4 \pm 2.7) \mathrm{cm}$ (run 2) thickness (mean and standard deviation of measured ice core thickness). Measurements of sea-ice temperature, thickness, and the initial ocean salinity were used to force the model, which has been used previously to model experiments in the RvGASIC (Garnett et al., 2019; Thomas et al., 2020). We used the Griewank and Notz (2013) gravity drainage parameterisation, because it performed well in previous studies (Thomas et al., 2020) and has tuning parameters shown to perform well for Arctic field data (Griewank and Notz, 2015). The model has two tuning parameters: the critical Rayleigh number, $R a_{\mathrm{c}}$, and the desalination strength, $\alpha$. We estimate an uncertainty on the modelling by running the model for each of the three sets of tuning parameters presented in Griewank and Notz (2015) (Table 4). The model is forced by measured temperature profiles and sea-ice thickness in lieu of modelled thermodynamics (Fig. 11). Cores and slabs were extracted according to Sect. 2.3.3 and sectioned vertically into 1 to $2 \mathrm{~cm}$ layers. Ice samples were melted and placed in a $20^{\circ} \mathrm{C}$ thermostatic bath. Conductivity was measured using a conductivity probe (Orion) and calibrated with certified reference material (Thermo Scientific Eutech Handheld Meters Calibration Solution). Bulk salinity was derived using the GSW toolbox (McDougall and Barker, 2011). We discarded three discrete samples (one from the cores and two from the slabs for run 1) because of punctured sample bags. A single wireharp profile was taken in the middle of the tank and used to derive $\phi$ and $S_{\mathrm{si}}$ (Eqs. 1 and 2).

The mass balance was constructed by conservation of mass and salt from the start of each run $\left(t_{0}\right)$ to the final sampling $\left(t_{\text {end }}\right)$. The conservation of mass gives

$m_{\mathrm{sys}}=m_{\mathrm{o}}+m_{\mathrm{si}}$,

where $m$ is mass, and the subscripts sys, o, and si indicate the experimental system, ocean, and sea-ice compartments, respectively. Noting that $m_{\text {sys }}=m_{\mathrm{o}}\left(t_{0}\right)$, the conservation of salt at the end of the experiment $\left(t_{\mathrm{end}}\right)$ gives

$m_{\mathrm{sys}} S_{\mathrm{o}}\left(t_{0}\right)=m_{\mathrm{o}} S_{\mathrm{o}}\left(t_{\mathrm{end}}\right)+m_{\mathrm{si}} \bar{S}_{\mathrm{si}}$.

Our desired variable is the vertically integrated bulk sea-ice salinity, $\bar{S}_{\text {si }}$, which we recover by substituting Eq. (10) into Eq. (11), giving

$\bar{S}_{\mathrm{si}}=r \Delta S+S_{\mathrm{o}}\left(t_{\mathrm{end}}\right)$,

where

$\Delta S=S_{\mathrm{o}}\left(t_{0}\right)-S_{\mathrm{o}}\left(t_{\mathrm{end}}\right)$

and $r$ gives the ratio of the mass of the experimental system to the mass of the sea ice at final sampling, such that

$r=\frac{h_{\mathrm{o}}\left(t_{0}\right) \rho_{\mathrm{o}}\left(t_{0}\right)}{h_{\mathrm{si}} \rho_{\mathrm{si}}}$.

The error on Eq. (12) was calculated by Gaussian propagation, such that

$u\left(\bar{S}_{\mathrm{si}}\right)=\sqrt{r^{2} \Delta S^{2}\left(\left(\frac{u(r)}{r}\right)^{2}+\left(\frac{u(\Delta S)}{\Delta S}\right)^{2}\right)+u\left(S_{\mathrm{O}}\right)^{2}}$,

where $u$ gives the uncertainty of the individual terms. The dominant uncertainty, accounting for $>95 \%$ of $u\left(\bar{S}_{\mathrm{si}}\right)$, propagates from $u(r)$ and derives chiefly from the variability in measured $h_{\mathrm{si}}$. The errors on $S_{\mathrm{o}}\left(t_{0}\right)$ and $S_{\mathrm{o}}\left(t_{\mathrm{end}}\right)$ are highly correlated given the stability of the salinity sensor over the short duration of the experiment, and as such $u(\Delta S) \ll$ $0.01 \mathrm{~g} \mathrm{~kg}^{-1}$ and has a negligible impact on $u\left(\bar{S}_{\mathrm{si}}\right)$. The sensitivity of $\bar{S}_{\text {si }}$ to our choice of $\rho_{\text {si }}$ is around $0.02\left(\mathrm{~g} \mathrm{~kg}^{-1}\right)$ 

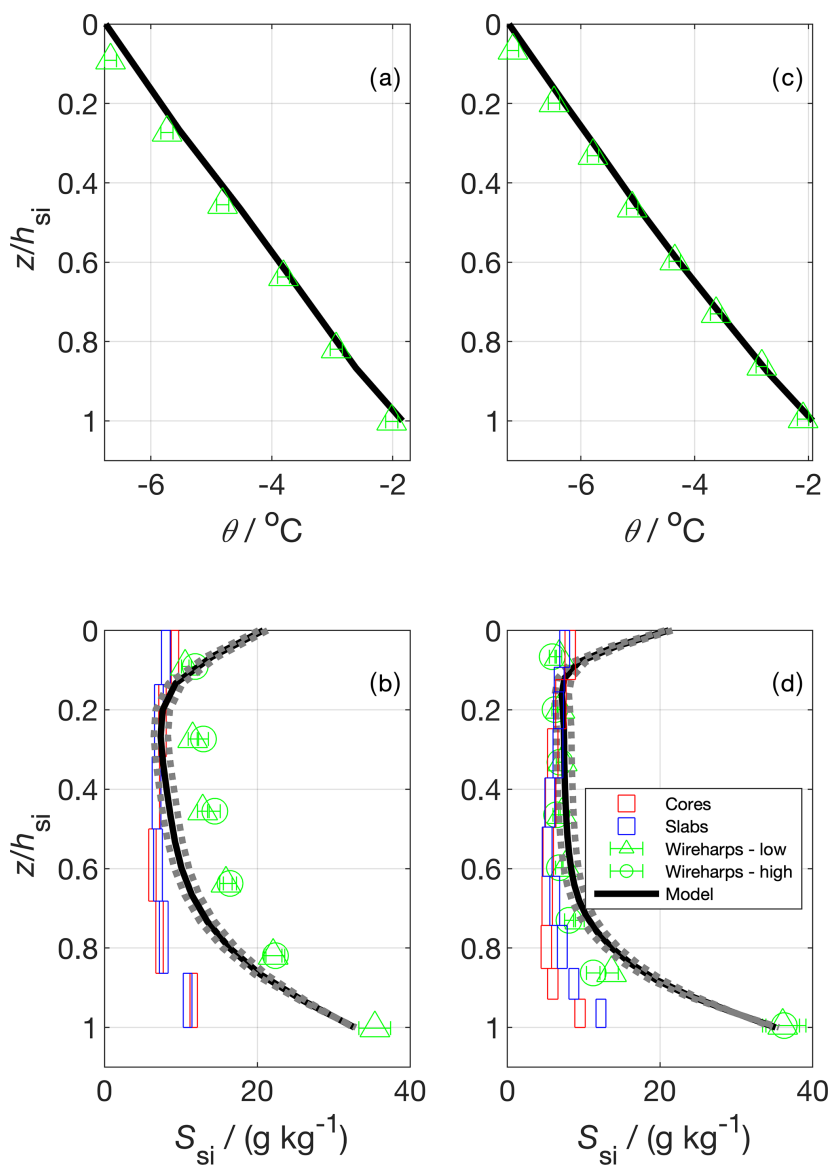

Figure 11. Vertical temperature (a and c) and bulk salinity profiles (b and d) for two experimental runs. In (a) and (c) the model temperature shows the model forcing, which was produced using measured temperature profiles; panels (b) and (d) show salinity estimated from cores, slabs (Cottier et al., 1999), wireharps (Notz et al., 2005), and a gravity drainage model. The horizontal box length shows the median 1 standard deviation from repeat measurements at a given depth (cores and slabs), and the vertical box length shows the depth covered by the sample layer. Wireharp errors were calculated using methodology presented in Zeigermann (2018). The model used the Griewank and Notz (2013) gravity drainage parameterisation with tuning parameters taken from Griewank and Notz (2015). The solid line represents their best estimate tuning parameter set. The dotted bounds on the model show output using two other plausible sets of tuning parameters presented in Griewank and Notz (2015).

$/\left(\mathrm{kg} \mathrm{m}^{-3}\right)$, such that a $20 \mathrm{~kg} \mathrm{~m}^{-3}$ increase in $\rho_{\text {si }}$ causes a $0.4 \mathrm{~g} \mathrm{~kg}^{-1}$ increase in our estimated $\bar{S}_{\mathrm{si}}$, which is well within our uncertainty bounds.

We first turn to the vertical profiles of $S_{\mathrm{si}}$ (Fig. 11). For both runs, the wireharp profile at low frequency including the electrical double-layer correction proposed by Notz et al. (2005) is very similar to the high-frequency wireharp profile without such correction. This confirms that at higher frequencies the impact of the double layer becomes less important, and no more correction to the profile is necessary. For simplicity, and because the high-frequency channel has not yet registered ice growth in the deepest run 1 sensor, we proceed by discussing only the low-frequency channel. For both runs, and for all profiles, there is a salinity maximum near the seaice-ocean interface $\left(z=h_{\mathrm{si}}\right)$. The model and the wireharps converge towards $S_{\mathrm{o}}$ as $z$ approaches $h_{\mathrm{si}}$. The cores and the slabs produce the lowest $S_{\mathrm{si}}$ near this lower interface, with the slabs giving higher $S_{\mathrm{si}}$ relative to the cores in this region in run 2 . For run 1 , the wireharps generally measure the highest $S_{\mathrm{si}}$, the cores and slabs are similar and measure the lowest $S_{\mathrm{si}}$, and the model is intermediate. For run 2, the cores, slabs, wireharps, and model are generally consistent between $z / h_{\mathrm{si}}=0.6$ to 0.1 . Near the upper interface, the model predicts higher $S_{\mathrm{si}}$ than the measurements, and the wireharps give the lowest $S_{\mathrm{si}}$. For run 1, the cores and slabs are consistent throughout, but the wireharps, model, and discrete samples generally disagree. Towards the sea-ice-atmosphere interface $(z=0)$, the wireharps produce minima in $S_{\mathrm{si}}$. The cores and slabs show an $\approx 1 \mathrm{~g} \mathrm{~kg}^{-1}$ increase in $S_{\mathrm{si}}$ for the shallowest layer relative to the layer below, forming a Cshaped profile. Modelled $S_{\mathrm{si}}$ at $z=0$ is around $10 \mathrm{~g} \mathrm{~kg}^{-1}$ greater than in the interior, forming a $\mathrm{C}$-shaped profile that is more pronounced than in the discrete samples at both interfaces. The difference in $\theta$ between the wireharps and the forcing is at most $0.2{ }^{\circ} \mathrm{C}$ which, depending on $S_{\mathrm{br}}$, translates to a $2 \%$ to $3 \%$ difference in $S_{\mathrm{si}}$.

The mass balance produces $\bar{S}_{\mathrm{si}}=(11.0 \pm 2.0) \mathrm{g} \mathrm{kg}^{-1}$ (run 1) and $\bar{S}_{\mathrm{si}}=(11.0 \pm 4.1) \mathrm{g} \mathrm{kg}^{-1}$ (run 2$)$ (mean and standard deviation, Table 4). These values represent the vertically integrated bulk sea-ice salinity, averaged over the tank footprint. We compare the measurements and model to the mass balance by calculating $\bar{S}_{\mathrm{si}}$ for the profile produced by each method at the end of each run. For the cores and slabs, we first averaged the individual layer measurements for each sample and then took the average of these samples to be $\bar{S}_{\mathrm{si}}$. For the wireharps, we linearly interpolated measured $S_{\mathrm{si}}$ to the midpoint between each measurement, and took the mean of these interpolated $S_{\mathrm{si}}$ to produce $\bar{S}_{\mathrm{si}}$. In this way, we more closely approximate the treatment of the cores and slabs, for which the edge of the bottommost layer is at $z=h_{\mathrm{si}}$. Model $\bar{S}_{\mathrm{si}}$ is the mean of the $S_{\mathrm{si}}$ of individual model layers. The cores and slabs perform similarly, underestimating the mass balance for each run. The wireharps overestimate the mass balance in run 1 and capture the run 2 mass balance to within 1 standard deviation. The best estimate model $\bar{S}_{\mathrm{si}}$ is consistent with the mass balance for both runs.

The underestimation of $\bar{S}_{\mathrm{si}}$ by the cores (Table 4 ) highlights a known bias in sea-ice core bulk salinity measurement, which is that of brine loss upon sampling. This bias is apparent in the vertical profiles (Fig. 11), where cores give the lowest estimates of $S_{\mathrm{si}}$ in the lower third of the profile, which we expect to be most affected by brine loss. The slabs perform similarly to the cores, potentially due to brine drainage during the shock freezing process. The slabs retain 
more brine than the cores in run 2, as shown by their higher $S_{\text {si }}$ in the lower portion and their higher $\bar{S}_{\text {si }}$. Previous work has tuned gravity drainage parameterisations to slab $S_{\mathrm{si}}$ measurements (Thomas et al., 2020), and these tuning parameters may therefore be biased to predict too much desalination. The wireharp performance is more variable, overestimating $\bar{S}_{\mathrm{si}}$ in run 1 and capturing the mass balance in run 2 . The performance of the model, forced with measured $\theta$ and $h_{\mathrm{si}}$, solely reflects the gravity drainage parameterisation and its tuning (Griewank and Notz, 2013, 2015), incorporating minimal error from thermodynamics. Only the model captures the mass balance for both runs. The mass balance is, for both runs, within the range of young sea-ice salinities observed in nature (Weeks and Lee, 1962; Notz and Worster, 2008).

\subsubsection{Quantifying sea-ice growth rates}

The growth rate of sea ice depends on the balance of fluxes at the sea-ice-ocean interface, the thermal conductivity of the sea ice $(K)$, sea-ice thickness $h_{\mathrm{si}}$, and the absolute sea-ice surface temperature $\left(T_{\mathrm{s}}\right)$. Growth rates in young sea ice have been observed to range from 2.7 to $12 \mathrm{~cm} \mathrm{~d}^{-1}$ (Wakatsuchi and Ono, 1983). Following Stefan (1889), the change in seaice thickness is

$\frac{\mathrm{d} h_{\mathrm{si}}}{\mathrm{d} t}=-F_{\mathrm{C}} /\left(\rho_{\mathrm{i}} L\right)$,

where $L$ gives the latent heat of fusion of water, and $F_{\mathrm{C}}$ gives the vertical conductive heat flux through the sea ice. $F_{\mathrm{C}}$, was calculated using

$F_{\mathrm{C}}=K\left(T_{\mathrm{s}}-T_{\mathrm{f}}\right) / h_{\mathrm{si}}$.

The vertically averaged thermal conductivity is $K=K_{\mathrm{i}}(1-$ $\phi)+K_{\mathrm{br}} \phi$, where the subscripts $\mathrm{i}$ and br indicate pure ice and brine, respectively. $T_{\mathrm{f}}$ is given by the salinity-dependent freezing point of the ocean, and $T_{\mathrm{S}}$ is found by iteratively solving the surface energy balance of the sea ice

$F_{\mathrm{L} \downarrow}-F_{\mathrm{L} \uparrow}+F_{\mathrm{S}}+F_{\mathrm{C}}=0$,

where sensible and latent heat fluxes have been neglected because the wind speed in our experiments was less than $0.1 \mathrm{~m} \mathrm{~s}^{-1}$. We parameterised the downwelling longwave flux, $F_{\mathrm{L} \downarrow}$, following Efimova (1961), as

$F_{\mathrm{L} \downarrow}=\sigma(0.746+0.0066(\psi / \mathrm{mbar})) T_{\mathrm{a}}^{4}$,

where $\sigma$ is the Stefan-Boltzmann constant, $\psi$ is the water vapour pressure, and $T_{\mathrm{a}}$ is the absolute temperature of the atmosphere. The upwelling longwave flux, $F_{\mathrm{L} \uparrow}$, is taken to be

$F_{\mathrm{L} \uparrow}=\sigma \epsilon T_{\mathrm{s}}^{4}$,

where the emissivity of sea ice is $\epsilon=0.99$. We compare the growth rate of our experimental sea ice to natural sea ice by

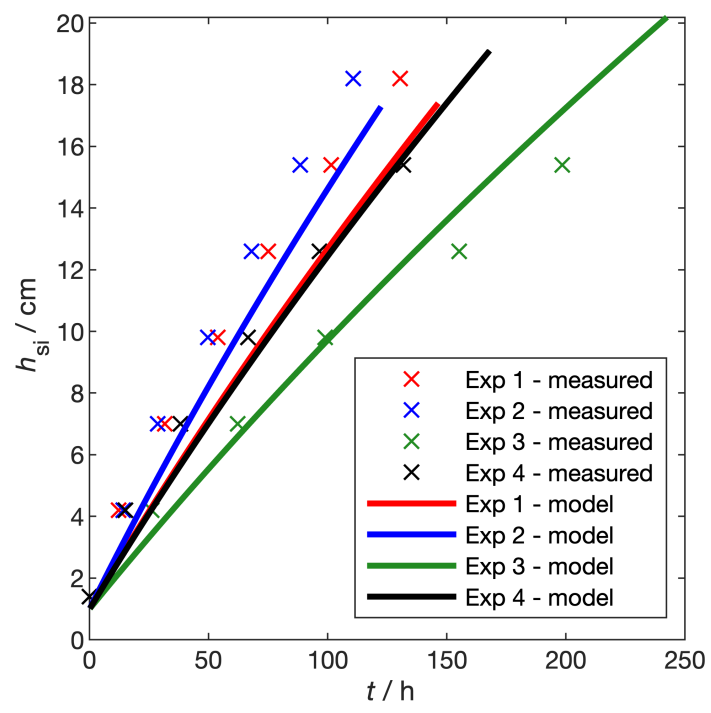

Figure 12. Thickness measured from temperature profiles during the experiments presented in Sect. 3.1.3 and modelled using Eq. (16).

modelling and measuring the growth rate of the four experimental runs presented in Sect. 3.2.1 and Table 2 (Fig. 12). When the temperature of a sensor at depth $z$ dipped by $0.1^{\circ} \mathrm{C}$ below the water temperature for $30 \mathrm{~min}$, we took $h_{\mathrm{si}}=z$. For each run, we forced the sea-ice growth and desalination model (Sect. 3.2.2, Thomas et al., 2020) with the mean $T_{\mathrm{a}}$ and $\psi$ during the freezing period, as measured by the weather station (Table 2). Incoming shortwave flux, $F_{\mathrm{S}}$, was taken to be $8 \mathrm{~W} \mathrm{~m}^{-2}$ based on measurements of PAR just above the seaice surface (Sect. 3.1.3). In this case, Eqs. (16) to (20) were used to calculate $T_{\mathrm{s}}, h_{\mathrm{si}}$, and the internal sea-ice temperature profile. $T_{\mathrm{f}}$ was calculated from the salinity-dependent freezing point of the model ocean.

Over the four experiments, measured growth rates range from $2 \mathrm{~cm} \mathrm{~d}^{-1}$ (experiment 3, highest air temperature) to $4 \mathrm{~cm} \mathrm{~d}^{-1}$ (experiment 2, lowest air temperature). These growth rates are within the range of those reported by Wakatsuchi and Ono (1983). Our growth rates are at the low end of this range, because the low wind speed in our facility effectively removes the latent and sensible heat fluxes present in the field. The change in $h_{\mathrm{si}}$ with time is not linear; rather, as has been observed before (Anderson, 1961), the rate of increase in $h_{\mathrm{si}}$ decreases with increasing $h_{\mathrm{si}}$. Modelled thickness captures the non-linearity in the measured growth rates and the order of the growth rates, with coldest temperatures producing fastest growth. Modelled thickness deviates from the measurements by up to $3 \mathrm{~cm}$.

Modelling thickness in this way is useful for planning experiments but - considering temperature profiles are measured during each experiment - measuring temperature and thickness gives better precision. Growth rates in the RvGASIC are within the range of those measured in the field 
Table 4. Results for the mean bulk salinity, $\bar{S}_{\mathrm{si}}$, calculated from five methodologies for two experimental runs. $t_{\mathrm{f}}$ is the duration of the freezing period, and $h_{\mathrm{si}}$ is the mean sea-ice thickness as measured in cores at the end of each run. The number of samples or profiles is given in brackets. With the exception of the model, all uncertainties are 1 standard deviation. Mass balance, core, and slab uncertainties were calculated based on repeat measurements. Wireharp uncertainties were calculated by propagation of the uncertainties on $R_{0}$ and $\theta$ for individual wire pairs. The model gives $\bar{S}_{\mathrm{si}}$ as predicted using the three parameter sets presented in Griewank and Notz (2015). Low bound: $R a_{\mathrm{c}}=3.23$, $\alpha=0.000681 \mathrm{~kg} \mathrm{~m}^{-3} \mathrm{~s}^{-1}$. Best estimate: $R a_{\mathrm{c}}=4.89, \alpha=0.000584 \mathrm{~kg} \mathrm{~m}^{-3} \mathrm{~s}^{-1}$. High bound: $R a_{\mathrm{c}}=7.10, \alpha=0.000510 \mathrm{~kg} \mathrm{~m}^{-3} \mathrm{~s}^{-1}$.

\begin{tabular}{|c|c|c|c|c|c|c|c|c|c|}
\hline \multirow[t]{2}{*}{ Run } & \multirow[t]{2}{*}{$t_{\mathrm{f}} / \mathrm{d}$} & \multirow[t]{2}{*}{$h_{\mathrm{si}} / \mathrm{cm}$} & \multicolumn{2}{|c|}{$S_{\mathrm{o}} /\left(\mathrm{g} \mathrm{kg}^{-1}\right)^{\mathrm{a}}$} & \multicolumn{5}{|c|}{$\bar{S}_{\mathrm{si}} /\left(\mathrm{g} \mathrm{kg}^{-1}\right)$} \\
\hline & & & Start & End & Mass balance & Cores & Slabs & Wireharp $^{\mathrm{b}}$ & Model \\
\hline 1 & 3.6 & $11.0 \pm 0.9(10)$ & 31.3 & 33.9 & $11.0 \pm 2.0(10)$ & $8.2 \pm 0.2(3)$ & $8.0 \pm 0.5(2)$ & $15.8 \pm 0.5$ & $12.9[12.0$ to 13.7$]$ \\
\hline 2 & 6.5 & $16.4 \pm 2.7(10)$ & 31.3 & 35.4 & $11.0 \pm 4.1(10)$ & $6.5 \pm 0.5(3)$ & $7.3 \pm 0.2(3)$ & $10.0 \pm 0.4$ & $11.6[10.8$ to 12.5$]$ \\
\hline
\end{tabular}

$\pm 0.1 \mathrm{~g} \mathrm{~kg}^{-1}$.

$\mathrm{b}$ low channel with $\gamma$ correction.

and are in agreement with thermodynamic modelling (Stefan, 1889).

\section{Conclusions}

We have described the Roland von Glasow Air-Sea-Ice Chamber (RvG-ASIC) and the suite of instruments supporting it, and we have given an overview of the protocols used to run experiments in the facility. We presented technical results from experiments in the facility showing (1) the time constant for air exchanging between our sealed chamber and the outside is $(0.66 \pm 0.07) \mathrm{d}$; (2) the time constant for mixing our tank is $(4.2 \pm 0.1) \mathrm{min}$; (3) the integrated irradiance of UV-A and PAR at $0{ }^{\circ} \mathrm{C}$ are 5.6 and $26.4 \mathrm{~W} \mathrm{~m}^{-2}$, respectively; (4) the temperature sensitivity of our LED and UV-A lighting is $(0.028 \pm 0.003) \mathrm{W} \mathrm{m}^{-2}$ and $(0.16 \pm 0.01) \mathrm{W} \mathrm{m}^{-2}{ }^{\circ} \mathrm{C}$, respectively; and (5) PAR intensity varies by around $10 \%$ near the centre of the tank but is as low as $60 \%$ near the corners. These technical results can be used to design and interpret future experiments. We also characterised our experimental sea ice showing that (6) the extinction coefficient of PAR in our experimental sea ice is within the range of previously observed PAR extinction coefficients in young sea ice; (7) the bulk salinity of our experimental sea ice is similar to that observed in nature and is in agreement with halo-dynamic modelling; and (8) the growth rate of our experimental sea ice is within the range of previously reported growth rates and is in reasonable agreement with thermodynamic modelling. This characterisation builds confidence that the RvG-ASIC produces experimental sea ice that is a reasonable analogue of natural sea ice for these important parameters.

The RvG-ASIC is a powerful and versatile tool for studying sea ice and has potential to investigate physics, chemistry, and biology. It is best suited to process studies, bridging the gap between numerical models and reality. The facility was named in honour of its founder, who won funding for the facility, led its design and construction, but sadly died in September 2015 before it could be put into full use.
Code and data availability. All data, plot scripts, and model code used to produce this article are provided as supplementary information accessible at https://doi.org/10.5281/zenodo.4419170 (Thomas, 2021).

Author contributions. MTh prepared the article with JF, JK, and DN. All authors were involved in some of the experimental work. MTh did the modelling. JF managed the facility from 2015 to 2018 , and OC managed the facility from 2018 to 2020, both under the supervision of JK.

Competing interests. The authors declare that they have no conflict of interest.

Special issue statement. This article is part of the special issue "Simulation chambers as tools in atmospheric research (AMT/ACP/GMD inter-journal SI)". It is not associated with a conference.

Acknowledgements. Roland von Glasow was instrumental in the design, construction, and scientific vision of the facility. Thanks to Bill Sturges, Dorothee Bakker, Martin Vancoppenolle, and Finlo Cottier for their time and scientific input to the RvG-ASIC. Jeremey Wilkinson and Martin King provided much useful advice and loaned us equipment. Thanks also to the technical support at UEA: Andy Macdonald, Stuart Rix, Dave Blomfield, Nick Griffin, Gareth Flowerdue, Ben McLeod, and Nick Garrard. This work received funding from the European Research Council under the European Union's Seventh Framework Programme (FP7-2007-2013, grant agreement no. 616938) and the Horizon 2020 research and innovation programme through the EUROCHAMP-2020 Infrastructure Activity under grant agreement no. 730997, as well as the University of East Anglia. Oliver Tooth, and Mathilde Tranter were supported by an internship granted by the Environmental Sciences department at UEA. 
Financial support. This research has been supported by the European Research Council, Seventh Framework Programme (FP7 Ideas (grant no. 616938)) and the H2020 Research Infrastructure EUROCHAMP-2020 (grant no. 730997).

Review statement. This paper was edited by Hartmut Herrmann and reviewed by Brice Loose and one anonymous referee.

\section{References}

Anderson, D. L.: Growth rate of sea ice, J. Glaciol., 3, 1170-1172, 1961.

Cottier, F., Eicken, H., and Wadhams, P.: Linkages between salinity and brine channel distribution in young sea ice, J. Geophys. Res.Oceans , 104, 15859-15871, 1999.

Cox, G. F. and Weeks, W. F.: Brine Drainage and Initial Salt Entrapment in Sodium Chloride Ice., Tech. rep., DTIC Document, 1975.

Cox, G. F. and Weeks, W. F.: Numerical simulations of the profile properties of undeformed first-year sea ice during the growth season, J. Geophys. Res., 93, 12449-12460, https://doi.org/10.1029/JC093iC10p12449, 1988.

De La Rosa, S., Maus, S., and Kern, S.: Thermodynamic investigation of an evolving grease to pancake ice field, Ann. Glaciol., 52, 206-214, 2011.

Dunkle, R. V. and Bevans, J.: An approximate analysis of the solar reflectance and transmittance of a snow cover, J. Meteorol., 13, 212-216, 1956.

Efimova, N.: On methods of calculating monthly values of net longwave radiation, Meterol. Gidrol., 10, 28-33, 1961.

Ehn, J., Granskog, M. A., Reinart, A., and Erm, A.: Optical properties of melting landfast sea ice and underlying seawater in Santala Bay, Gulf of Finland, J. Geophys. Res.-Oceans, 109, C09003, https://doi.org/10.1029/2003JC002042, 2004.

Eide, L. and Martin, S.: The formation of brine drainage features in young sea ice, J. Glaciol., 14, 137-154, 1975.

Fritsen, C., Lytle, V., Ackley, S., and Sullivan, C.: Autumn bloom of Antarctic pack-ice algae, Science, 266, 782-784, 1994.

Garnett, J., Halsall, C., Thomas, M., France, J., Kaiser, J., Graf, C., Leeson, A., and Wynn, P.: Mechanistic insight into the uptake and fate of persistent organic pollutants in sea ice, Environ. Sci. Technol., 53, 6757-6764, 2019.

Gosink, T. A., Pearson, J. G., and Kelley, J. J.: Gas movement through sea ice, Nature, 263, 41, https://doi.org/10.1038/263041a0, 1976.

Grenfell, T. C. and Maykut, G. A.: The optical properties of ice and snow in the Arctic Basin, J. Glaciol., 18, 445-463, 1977.

Griewank, P. J. and Notz, D.: Insights into brine dynamics and sea ice desalination from a 1-D model study of gravity drainage, J. Geophys. Res.-Oceans, 118, 3370-3386, 2013.

Griewank, P. J. and Notz, D.: A 1-D modelling study of Arctic sea-ice salinity, The Cryosphere, 9, 305-329, https://doi.org/10.5194/tc-9-305-2015, 2015.

Hare, A., Wang, F., Barber, D., Geilfus, N.-X., Galley, R., and Rysgaard, S.: $\mathrm{pH}$ evolution in sea ice grown at an outdoor experimental facility, Mar. Chem., 154, 46-54, 2013.
Hof, V.: The influence of varying freezing temperature on light transfer in thin sea ice, MSc thesis, University Hamburg, Hamburg, Germany, 2019.

Jeffery, N., Hunke, E., and Elliott, S.: Modeling the transport of passive tracers in sea ice, J. Geophys. Res.-Oceans, 116, C07020, https://doi.org/10.1029/2010JC006527, 2011.

Jiang, S., Stamnes, K., Li, W., and Hamre, B.: Enhanced solar irradiance across the atmosphere-sea ice interface: a quantitative numerical study, Appl. Opt., 44, 2613-2625, 2005.

Kauko, H. M., Taskjelle, T., Assmy, P., Pavlov, A. K., Mundy, C., Duarte, P., Fernández-Méndez, M., Olsen, L. M., Hudson, S. R., Johnsen, G., Elliott, A., Wang, F., and Granskog, M. A.: Windows in Arctic sea ice: Light transmission and ice algae in a refrozen lead, J. Geophys. Res.-Biogeo., 122, 1486-1505, 2017.

King, M., France, J., Fisher, F., and Beine, H.: Measurement and modelling of UV radiation penetration and photolysis rates of nitrate and hydrogen peroxide in Antarctic sea ice: An estimate of the production rate of hydroxyl radicals in first-year sea ice, J. Photochem. Photobiol. A, 176, 39-49, 2005.

Kotovitch, M., Moreau, S., Zhou, J., Vancoppenolle, M., Dieckmann, G. S., Evers, K.-U., Van der Linden, F., Thomas, D. N., Tison, J.-L., and Delille, B.: Air-ice carbon pathways inferred from a sea ice tank experiment, Elementa, 4, 000112, https://doi.org/10.12952/journal.elementa.000112, 2016.

Küpper, F. C., Carpenter, L. J., McFiggans, G. B., Palmer, C. J., Waite, T. J., Boneberg, E.-M., Woitsch, S., Weiller, M., Abela, R., Grolimund, D., Potin, P., Butler, A., Luther III, G. W., Kroneck, P. M. H., Meyer-Klaucke, W., and Feiters, M. C.: Iodide accumulation provides kelp with an inorganic antioxidant impacting atmospheric chemistry, P. Natl. Acad. Sci. USA, 105, 6954-6958, 2008.

Loose, B., McGillis, W., Schlosser, P., Perovich, D., and Takahashi, T.: Effects of freezing, growth, and ice cover on gas transport processes in laboratory seawater experiments, Geophys. Res. Lett., 36, L05603, https://doi.org/10.1029/2008GL036318, 2009.

Loose, B., Miller, L. A., Elliott, S., and Papakyriakou, T.: Sea ice biogeochemistry and material transport across the frozen interface, Oceanography, 24, 202-218, 2011.

Lovely, A., Loose, B., Schlosser, P., McGillis, W., Zappa, C., Perovich, D., Brown, S., Morell, T., Hsueh, D., and Friedrich, R.: The Gas Transfer through Polar Sea ice experiment: Insights into the rates and pathways that determine geochemical fluxes, J. Geophys. Res.-Oceans, 120, 8177-8194, https://doi.org/10.1002/2014JC010607, 2015.

Marks, A. A., Lamare, M. L., and King, M. D.: Optical properties of sea ice doped with black carbon - an experimental and radiativetransfer modelling comparison, The Cryosphere, 11, 2867-2881, https://doi.org/10.5194/tc-11-2867-2017, 2017.

May, N., Quinn, P., McNamara, S., and Pratt, K.: Multiyear study of the dependence of sea salt aerosol on wind speed and sea ice conditions in the coastal Arctic, J. Geophys. Res.-Atmos., 121, 9208-9219, 2016.

McDougall, T. J. and Barker, P. M.: Getting started with TEOS10 and the Gibbs Seawater (GSW) oceanographic toolbox, SCOR/IAPSO WG, 127, 1-28, 2011.

McPhee, M. G., Maykut, G. A., and Morison, J. H.: Dynamics and thermodynamics of the ice/upper ocean system in the marginal ice zone of the Greenland Sea, J. Geophys. Res.-Oceans, 92, 7017-7031, 1987. 
Middleton, C., Thomas, C., De Wit, A., and Tison, J.-L.: Visualizing brine channel development and convective processes during artificial sea-ice growth using Schlieren optical methods, J. Glaciol., 62, 1-17, 2016.

Miller, L. A., Fripiat, F., Else, B. G., Bowman, J. S., Brown, K. A., Collins, R. E., Ewert, M., Fransson, A., Gosselin, M., Lannuzel, D., Meiners, K. M., Michel, C., Nishioka, J., Nomura, D., Papadimitriou, S., Russell, L. M., Sørensen, L. L., Thomas, D. N., Tison, J.-L., Van Leeuwe, M. A., Vancoppenolle, M., Wolff, E. W., and Zhou, J.: Methods for biogeochemical studies of sea ice: The state of the art, caveats, and recommendations, Elementa, 3, 000038, https://doi.org/10.12952/journal.elementa.000038, 2015.

Naumann, A. K., Notz, D., Håvik, L., and Sirevaag, A.: Laboratory study of initial sea-ice growth: properties of grease ice and nilas, The Cryosphere, 6, 729-741, https://doi.org/10.5194/tc-6729-2012, 2012.

Niedrauer, T. M. and Martin, S.: An experimental study of brine drainage and convection in young sea ice, J. Geophys. Res.Oceans, 84, 1176-1186, 1979.

Nomura, D., Yoshikawa-Inoue, H., and Toyota, T.: The effect of sea-ice growth on air-sea $\mathrm{CO}_{2}$ flux in a tank experiment, Tellus B, 58, 418-426, 2006.

Notz, D.: Thermodynamic and fluid-dynamical processes in sea ice, Phd thesis, University of Cambridge, 2005

Notz, D. and Worster, M. G.: In situ measurements of the evolution of young sea ice, J. Geophys. Res.-Oceans, 113, C03001, https://doi.org/10.1029/2007JC004333, 2008.

Notz, D. and Worster, M. G.: Desalination processes of sea ice revisited, J. Geophys. Res.-Oceans, 114, C05006, https://doi.org/10.1029/2008JC004885, 2009.

Notz, D., Wettlaufer, J. S., and Worster, M. G.: A non-destructive method for measuring the salinity and solid fraction of growing sea ice in situ, J. Glaciol., 51, 159-166, 2005.

Perovich, D. K. and Grenfell, T. C.: Laboratory studies of the optical properties of young sea ice, J. Glaciol., 27, 331-346, 1981.

Perovich, D. K. and Richter-Menge, J. A.: Surface characteristics of lead ice, J. Geophys. Res.-Oceans, 99, 16341-16350, 1994.

Rees Jones, D. W. and Worster, M. G.: A physically based parameterization of gravity drainage for sea-ice modeling, J. Geophys. Res.-Oceans, 119, 5599-5621, https://doi.org/10.1002/2013JC009296, 2014.

Rysgaard, S., Wang, F., Galley, R. J., Grimm, R., Notz, D., Lemes, M., Geilfus, N.-X., Chaulk, A., Hare, A. A., Crabeck, O., Else, B. G. T., Campbell, K., Sørensen, L. L., Sievers, J., and Papakyriakou, T.: Temporal dynamics of ikaite in experimental sea ice, The Cryosphere, 8, 1469-1478, https://doi.org/10.5194/tc-81469-2014, 2014.

Shaw, M., Carpenter, L., Baeza-Romero, M., and Jackson, A.: Thermal evolution of diffusive transport of atmospheric halocarbons through artificial sea-ice, Atmos. Environ., 45, 6393-6402, 2011

Stefan, J.: Über einige Probleme der Theorie der Warmeleitung (in German), Sitzungsberichte der Math-Natur Classe der Kaiserlichen, Akad der Weissenschaften, 98, 473-484, 1889.

Style, R. W. and Worster, M. G.: Frost flower formation on sea ice and lake ice, Geophys. Res. Lett., 36, L11501, https://doi.org/10.1029/2009GL037304, 2009.
Taskjelle, T., Hudson, S. R., Granskog, M. A., Nicolaus, M., Lei, R., Gerland, S., Stamnes, J. J., and Hamre, B.: Spectral albedo and transmittance of thin young A rctic sea ice, J. Geophys. Res.Oceans, 121, 540-553, 2016.

Thomas, M.: SI for final submission of: The Roland von Glasow Air-Sea-Ice Chamber (RvG-ASIC): an experimental facility for studying ocean/sea-ice/atmosphere interactions (Version Final submission), Zenodo, https://doi.org/10.5281/zenodo.4419170, 2021.

Thomas, M., Vancoppenolle, M., France, J., Sturges, W., Bakker, D., Kaiser, J., and von Glasow, R.: Tracer measurements in growing sea ice support convective gravity drainage parameterizations, J. Geophys. Res.-Oceans, 125, e2019JC015791, https://doi.org/10.1029/2019JC015791, 2020.

Tison, J.-L., Haas, C., Gowing, M. M., Sleewaegen, S., and Bernard, A.: Tank study of physico-chemical controls on gas content and composition during growth of young sea ice, J. Glaciol., 48, 177191, 2002.

Turner, A. K., Hunke, E. C., and Bitz, C. M.: Two modes of sea-ice gravity drainage: A parameterization for large-scale modeling, J. Geophys. Res.-Oceans, 118, 2279-2294, 2013.

Vancoppenolle, M., Goosse, H., De Montety, A., Fichefet, T., Tremblay, B., and Tison, J.-L.: Modeling brine and nutrient dynamics in Antarctic sea ice: The case of dissolved silica, J. Geophys. Res.-Oceans, 115, C02005, https://doi.org/10.1029/2009JC005369, 2010.

Vancoppenolle, M., Madec, G., Thomas, M., and McDougall, T. J.: Thermodynamics of Sea Ice Phase Composition Revisited, J. Geophys. Res.-Oceans, 124, 615-634, https://doi.org/10.1029/2018JC014611, 2019.

Wakatsuchi, M. and Ono, N.: Measurements of salinity and volume of brine excluded from growing sea ice, J. Geophys. Res.Oceans, 88, 2943-2951, 1983.

Weast, R. C.: Handbook of Chemistry and Physics, Chemical Rubber Co., Cleveland, Ohio, USA, 1971.

Weeks, W. F. and Lee, O. S.: The salinity distribution in young sea ice, vol. 98, US Army Cold Regions Research and Engineering Laboratory, Corps of Engineers, Hanover, New Hampshire, USA, https://doi.org/10.14430/arctic3562, 1962.

Wells, A., Wettlaufer, J., and Orszag, S.: Brine fluxes from growing sea ice, Geophys. Res. Lett., 38, L04501, https://doi.org/10.1029/2010GL046288, 2011.

Wettlaufer, J., Worster, M. G., and Huppert, H. E.: The phase evolution of young sea ice, Geophys. Res. Lett., 24, 1251-1254, 1997.

Worster, M. G. and Rees Jones, D. W.: Sea-ice thermodynamics and brine drainage, Philos. T. Roy. Soc. A, 373, 20140166, https://doi.org/10.1098/rsta.2014.0166, 2015.

Zeigermann, L. M.: Desalination processes in thin sea ice during freezing and melting, MSc thesis, University Hamburg, Hamburg, Germany, 2018.

Zhou, J., Tison, J.-L., Carnat, G., Geilfus, N.-X., and Delille, B.: Physical controls on the storage of methane in landfast sea ice, The Cryosphere, 8, 1019-1029, https://doi.org/10.5194/tc8-1019-2014, 2014. 